\title{
Drought and Salinity Stress Responses and Microbe-Induced Tolerance in Plants
}

\author{
Ying Ma*, Maria Celeste Dias and Helena Freitas \\ University of Coimbra, Centre for Functional Ecology, Department of Life Sciences, Coimbra, Portugal
}

Drought and salinity are among the most important environmental factors that hampered agricultural productivity worldwide. Both stresses can induce several morphological, physiological, biochemical, and metabolic alterations through various mechanisms, eventually influencing plant growth, development, and productivity. The responses of plants to these stress conditions are highly complex and depend on other factors, such as the species and genotype, plant age and size, the rate of progression as well as the intensity and duration of the stresses. These factors have a strong effect on plant response

OPEN ACCESS

Edited by:

Ingo Ebersberger,

Goethe University Frankfurt, Germany

Reviewed by:

Michele Grieco,

Martin Luther University of

Halle-Wittenberg, Germany

Dilfuza Egamberdieva,

Leibniz Center for Agricultural

Landscape Research (ZALF),

Germany

*Correspondence:

Ying $\mathrm{Ma}$

cathymaying@gmail.com; yingma@uc.pt

Specialty section:

This article was submitted to Technical Advances in Plant Science, a section of the journal

Frontiers in Plant Science

Received: 05 August 2020

Accepted: 19 October 2020

Published: 13 November 2020

Citation:

Ma Y, Dias MC and Freitas H (2020)

Drought and Salinity Stress

Responses and Microbe-Induced

Tolerance in Plants.

Front. Plant Sci. 11:591911.

doi: 10.3389/fp/s.2020.591911 and define whether mitigation processes related to acclimation will occur or not. In this review, we summarize how drought and salinity extensively affect plant growth in agriculture ecosystems. In particular, we focus on the morphological, physiological, biochemical, and metabolic responses of plants to these stresses. Moreover, we discuss mechanisms underlying plant-microbe interactions that confer abiotic stress tolerance.

Keywords: drought, salinity, photosynthesis, osmotic adjustment, metabolic regulation, plant-microbe interactions, phytohormonal regulation, plant adaptations

\section{INTRODUCTION}

Plant growth, development, productivity, and resistance to climatic stresses are currently the major topics of interest for agriculture and plant-based biotechnologies. Both biotic (e.g., phytopathogens) and abiotic stresses (e.g., drought, salinity, flood, storm, and extreme temperatures) cause enormous losses in agricultural production (Fraire-Velázquez and Balderas-Hernández, 2013). In the past decades, tremendous progress has been made in understanding the mechanisms underlying plant resistance/tolerance to individual biotic and/or abiotic stresses. Moreover, plant responses to various stresses and their positive or negative impacts on plant growth have been comprehensively studied (Abuqamar et al., 2009). However, plants existing in nature must simultaneously cope with diverse and interacting stresses that generally occur simultaneously or in sequence (Pandey et al., 2015). It is well known that drought and salinity are the two foremost abiotic stresses that reduce the global productivity of major crops (Kaushal and Wani, 2016; Singh et al., 2018). So far, our current knowledge about the key processes involved in plant adaptations to abiotic stress conditions is still very limited. Therefore, there is a need to understand the mechanisms of plant tolerance/adaptation and mitigation strategies to abiotic stresses.

In the present review, we focus on recent advances in understanding the mechanisms involved in plant response/adaption to the selected environmental stresses (e.g., drought and salinity) at the morphological (e.g., root morphology, plant growth, and yield), physiological and biochemical (e.g., photosynthesis, pigment, osmotic adjustment, and antioxidants), and metabolomic (e.g., 
metabolite adjustments) levels, as well as plant-microbe interactions that confer abiotic stress tolerance in plants (Figure 1).

\section{PLANT ADAPTATION TO DROUGHT AND SALINITY STRESS}

Plant physiology is significantly affected by abiotic/climatic stresses. It is well known that climate change and environmental extremes induce and enhance the impact of abiotic stresses (particularly drought and salinity) on plant fitness and performance (Kaushal and Wani, 2016). The positive and negative impacts of drought and salinity on plant growth and development are summarized in Figure 2. Besides all the negative effects induced by drought and salinity on plant performance, to some extent, drought or salinity may result in some positive effects on plants (Raza et al., 2019). For instance, Hatzig et al. (2018) found that drought stress showed a positive transgenerational impact on seedling vigor of Brassica napus. They attributed this to heterotic effects, the altered reservoir of seed storage metabolites, and inter-generational stress memory formed by stress-induced changes in the epigenome of the seedling. Salinity at certain concentrations may also cause an increase in clonal/ sexual reproduction, thus improving plant fecundity (Van Zandt et al., 2003). This effect strongly depends on the genotypes/ cultivar and plant developmental stage.

To meet the needs of developing sustainable agriculture and improving food safety, it is necessary to grow stress-tolerant plants and understand the mechanisms underlying their tolerance. In general, plant responses to abiotic stresses vary in morphology, physiology, biochemistry, and metabolism, which will be discussed in the following sections.

\section{PLANT MORPHOLOGICAL RESPONSES TO DROUGHT AND SALINITY STRESS}

Since water is vital to life on earth, drought or osmotic stress may significantly affect many aspects of plant morphology and physiology (Suwa et al., 2006; Rahdari and Hoseini, 2012). Exposure of plants to drought stress generally results in a significant reduction of growth and yield of crops such as Hordeum vulgare, Oryza sativa, Triticum aestivum, Zea mays (Kamara et al., 2003; Samarah, 2005; Rampino et al., 2006; Lafitte et al., 2007) due to low humidity in plants, high intensity of sunlight, high temperature caused by drought with enhanced respiration, photosynthesis, and enzyme activity in plants (Fathi and Tari, 2016). In the early phase of drought stress, gradual water depletion causes a decrease in shoot growth, whereas root growth is maintained, resulting in an enhanced root/ shoot ratio (Bogeat-Triboulot et al., 2007). Plants subjected to moderate drought normally show a slight change in their growth pattern, along with only a small increase in the root mass fraction (RMF) calculated as the proportion of plant dry mass in roots. The plants seem to maintain their aboveground growth and, therefore, their competitiveness for aboveground resources, as long as possible under moderate drought. In contrast, plants exposed to severe drought, Poorter et al. (2012) reported that when the biomass is reduced by more than $50 \%$ compared with control plants, respond with a strong increase in RMF, which can be largely attributed to a decrease in the growth of the stems. Under the moderate or severe drought conditions, the accumulation of salts and ions in soil upper layers leads to osmotic stress and ion toxicity in plants. With an increase in the degree of drought stress, turgor pressure of the plant cells decreases, causing plant cell wall wrinkled

\section{Positive impact}

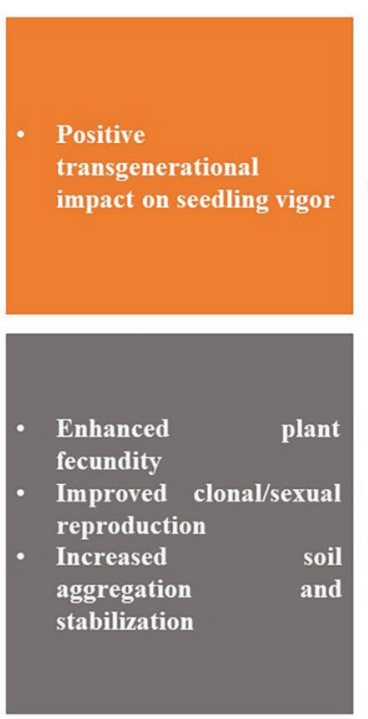

Negative impact
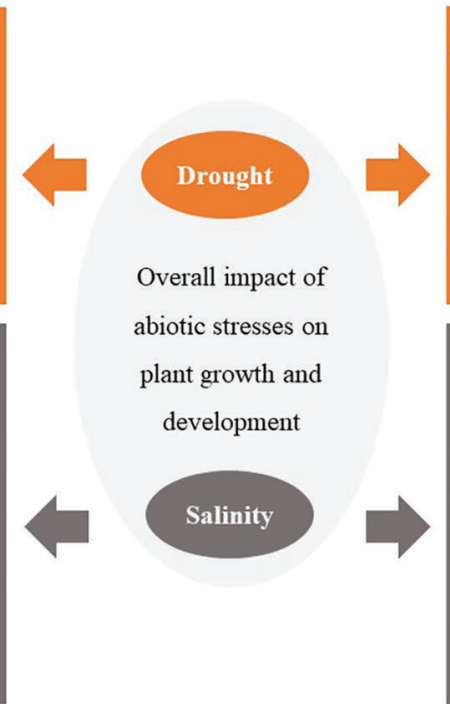

Nutrient deficiencies

Plant dehydration and even death

Drought induced salt and ion accumulation,

thus osmotic stress

- Hamper photosynthesis activities

- Lipid peroxidation and membrane

deterioration

Imbalance between antioxidant defenses and ROS

Leaf abscission

Soil compaction

Inorganic/organic contamination

Diminished microbial activity and diversity

Ion toxicity (Cr, $\mathrm{Na}^{+}$, and boron)

Osmotic stress

Nutrient (N, Ca, K, P, Fe, and $\mathrm{Zn}$ ) defíciency

Oxidative stress reduced water uptake

Reduced photosynthesis through a reduction

in leaf area, chlorophyll content, stomatal

conductance and photosystem II efíciency

Diminished reproductivity by inhabiting

microsporogenesis and stamen filament

elongation

FIGURE 1 | Impacts of drought and salinity on plant growth. The arrows point to an effect and the colors are the origins (cause). For example, from Drought $\rightarrow$ its effects on plants, which the arrows and boxes are orange; Salinity $\rightarrow$ its effects on plants, which the arrow and boxes are colored dark gray. 
and loose. These biophysical responses may eventually reduce the size and number of the leaves as well as fresh weight and water content of plants (Jaleel et al., 2009; Fathi and Tari, 2016). Under mild or moderate drought stress, the roots may change their architecture and allocation of resources (water and nutrients) to avoid dehydration (Smith and De Smet, 2012; Hasibeder et al., 2015). However, under severe drought stress conditions, the roots shrink, and the photosystem II becomes dysfunctional in the leaves (Fathi and Tari, 2016). During soil (low soil moisture) drought and atmospheric aridity (high vapor pressure deficit), the profiles of root exudation (e.g., composition and concentration) may also shift, therefore, influencing the rhizosphere soils properties (Henry et al., 2007; Song et al., 2012). Besides, the availability and plant uptake of nutrients in soils can be affected by drought, since nutrients are carried to the roots by water. Drought stress may further reduce nutrient diffusion and mass flow of water-soluble nutrients (Selvakumar et al., 2012).

Salinity adversely affects seed germination, plant growth, and development, causing significant crop yield losses worldwide (AbdElgawad et al., 2016). As a consequence of salinity stress, seed germination decreases by regulating the abscisic acid (ABA) concentration via changes in 9-cis-epoxycarotenoid dioxygenase3/salt tolerant1 (NCED/STO1) expression (Wang et al., 2015). Moreover, salinity stress can regulate the activity of two ethylene biosynthesis enzymes, namely 1-aminocyclopropane-1-carboxylic acid (ACC) synthase and ACC oxidase. It is well known that ethylene has an essential role in stimulating the dormancy-breakage and seed germination of several plant species by inhibiting ABA functions (Ribeiro and Barros, 2006; El-Maarouf-Bouteau et al., 2015) and can contribute to seed tolerance to salinity (Silva et al., 2014). Therefore, the balance between ethylene and $\mathrm{ABA}$ is crucial to modulate seed germination to cope with salinity stress (González-Guzmán et al., 2002). Sibole et al. (2003) reported that stem and petiole growth of Medicago arborea and Melaleuca citrina was inhibited under salinity stress. Besides, salinity stress may significantly influence carbon and nitrogen metabolism in plants (Obata and Fernie, 2012) and induce alterations in the concentrations of tricarboxylic acid cycle intermediates, sugars, and amino acids in plants to maintain metabolic homeostasis under increasing salt concentrations (Richter et al., 2015; Li et al., 2017).

In recent decades, remarkable advances have been made in various domains of stress physiology, among which long- and short-distance signaling plays an essential role in the feedforward and the feed-back control of photosynthesis in response to drought and salinity. Several studies indicate that signaling may act even before that the cell biophysical alterations occur (Mittler, 2006; Huang et al., 2012). It is well known that signaling pathways causing plants' responses to various stresses are interconnected at many levels. To adapt to drought and salinity stresses, plants have developed diverse stress-responsive signaling pathways and activated defense mechanisms (Huang et al., 2012). Plants can employ multiple stress perception and signal transduction pathways, which can crosstalk at different steps in the pathways. When drought and salinity occur simultaneously, plants can also exhibit strategic defense responses which could be distinctive from the response to either individual stress (Koussevitzky et al., 2008). Thus, the molecular and metabolic responses to a combination of stresses are unique and cannot be extrapolated from plant response to the individual stress (Mittler, 2006).

\section{PLANT PHYSIOLOGICAL AND BIOCHEMICAL RESPONSE TO DROUGHT AND SALINITY}

Early responses to drought and salinity are very similar since both induce water stress that leads to a slowdown in growth, a decrease in stomatal aperture, and a nutrient deficiency (such as $\mathrm{K}^{+}$and $\mathrm{Ca}^{2+}$ ). However, during long term exposure to salt, besides dehydration, plants experience ionic stress, which leads to leaf senescence and photosynthesis impairment (that in turn exerts an additional negative effect on growth; Chaves et al., 2009). When plants are exposed to long-term drought stress, continued root elongation occurs, which may be explained by the plant's need to reach groundwater (Brunner et al., 2015). While under long-term salinity stress, heavier roots may accumulate higher amounts of chloride. The excessive accumulation of ions, predominantly $\mathrm{Na}^{2+}$, affects negatively the photosynthetic components, therefore, reducing enzyme activities and pigment synthesis. These stressful conditions decrease the $\mathrm{CO}_{2}$ assimilation rate, and the excess of light absorbed that is not used by the plant can lead to an increase in reactive oxygen species (ROS) production and consequently oxidative stress. Many species possessing salt exclusion mechanisms can prevent salt entry in plant cells, or they can minimize salt concentration in the cytoplasm by compartmentalizing salt in the vacuoles (Khan et al., 2019). These strategies reduce the negative effects on photosynthesis and other metabolic processes. In salinity acclimated plants, some metabolites related to primary metabolism (e.g., carbohydrates, amino acid, and nitrogen) play an important protective role acting as osmolytes (protecting membranes and protein) and ROS scavengers (Sharma et al., 2019).

\section{Photosynthesis}

Photosynthesis is one of the main processes affected by drought and salinity (Chaves et al., 2009). Stomata have two important key functions in plants: one is to regulate transpiration, which supplies plants with nutrients and regulates leaf temperature, and the other is to control $\mathrm{CO}_{2}$ entry into the leaf. Under drought conditions, one of the first response of plants is a reduction in the stomatal aperture, and when the stress event continues, both changes in leaf photochemistry and/or carbon metabolism are also impaired, therefore, negatively affecting photosynthesis (Dias et al., 2014; Vasques et al., 2016; Araújo et al., 2019). The reduction of the stomata aperture width (stomatal closure) prevents the loss of water to the atmosphere and this protection mechanism is considered an adaptation response of plants to the onset of drought conditions (Saradadevi et al., 2017). Besides, $\mathrm{CO}_{2}$ diffusion through the leaf mesophyll cells (mesophyll conductance) is also affected, mostly due to 
changes in leaf biochemistry, membrane permeability (aquaporin activity), and leaf shrinkage (modification of the intercellular spaces and structures; Chaves et al., 2009). Following stomatal closure, the low $\mathrm{CO}_{2}$ availability in the leaf intercellular spaces can impair the biochemical reactions. This result in a reduction or de-activation of the enzyme ribulose 1,5-bisphosphate carboxylase/oxygenase (RuBisCO), or other Calvin cycle enzymes, such as ribulose-5-phosphate kinase, or a decrease in the substrate of RuBisCO (regeneration of RuBP; Dias and Brüggemann, 2011; Galmés et al., 2011; Perdomo et al., 2017; Wang et al., 2018a). RuBisCO amount, activity, and alterations at the transcript level were reported even under mild water deficit (Zhang et al., 2013). Also, the ROS generated under stress conditions in the chloroplast is reported to damage ATP synthase and decrease ATP production, which consequently leads to lower ribulose-1,5-bisphosphate (RuBP) regeneration (Pinheiro and Chaves, 2011).

When plants are exposed to high light intensities and the inhibition of biochemical reactions by drought conditions precedes the inhibition of light-dependent reactions of photosynthesis, the rate of reducing power production can overcome the rate of its use in the Calvin cycle. Under this condition, the excess of light energy has to be dissipated to avoid overexcitation, and consequential damages in the photosynthetic machinery, particularly in photosystem II (PSII). Plants possess a range of protective mechanisms against the excess of light energy that decrease the probability of damage in PS reaction centers. These mechanisms include dissipation of absorbed light energy as thermal energy (non-photochemical quenching, involving the xanthophyll and the lutein cycle), pseudocyclic electron flow coupled to ROS scavenging systems, PSI cyclic electron flow, increased photorespiration, changes in leaf angle, and chloroplast avoidance movement (Pinheiro and Chaves, 2011; Wang et al., 2018b). Additionally, the protection of anthocyanins over chlorophylls also contributes to plant photoprotection (Gould et al., 2002). Anthocyanins function as light screening pigments, filtering the extra photons that would be damaging if absorbed by chlorophylls (Nichelmann and Bilger, 2017; Gould et al., 2018). Moreover, the anthocyanins located in the leaf epiderm seem more efficient to photoprotect the subjacent mesophyll from photoinhibition (Lo Piccolo et al., 2018).

Under salinity stress, stomata closure and consequent reduction of the intercellular $\mathrm{CO}_{2}$ concentration are the main causes of photosynthesis impairment. This decrease leads to reductions in the carbohydrate pool and protein concentration. Salt stress also affects other photosynthetic components such as the efficiency of RuBisCO for carbon fixation, and the enzymes related to chlorophylls and carotenoid biosynthesis (Demetriou et al., 2007; Chaves et al., 2009). The light reactions of photosynthesis were reported to be very susceptible to salt stress. Photosynthesis inhibition by salinity seems to be partially associated with the PSII complex. Salt stress reduces the PSII activity and the quantum yield of PSII electron transport and affects the photosynthetic pigment-protein complexes (Demetriou et al., 2007). Changes in these photosynthetic parameters depend on the intensity and duration of the stress, but plant species is also an important factor. For instance, both Sorghum bicolor salt-sensitive and -tolerant genotypes showed a reduction in net $\mathrm{CO}_{2}$ assimilation rate and PSII efficiency $\left(\mathrm{F}_{\mathrm{v}} / \mathrm{F}_{\mathrm{m}}\right.$ and $\left.\Phi_{\mathrm{PSII}}\right)$, but in the sensitive genotype, these effects were stronger (Sui et al., 2015). In several $O$. sativa cultivars with different salttolerances, the $\Phi_{\mathrm{PSII}}$ and net $\mathrm{CO}_{2}$ assimilation rate were also negatively affected, but the $\mathrm{F}_{\mathrm{v}} / \mathrm{F}_{\mathrm{m}}$ was maintained under optimal values (0.75-0.80; Yang et al., 2020).

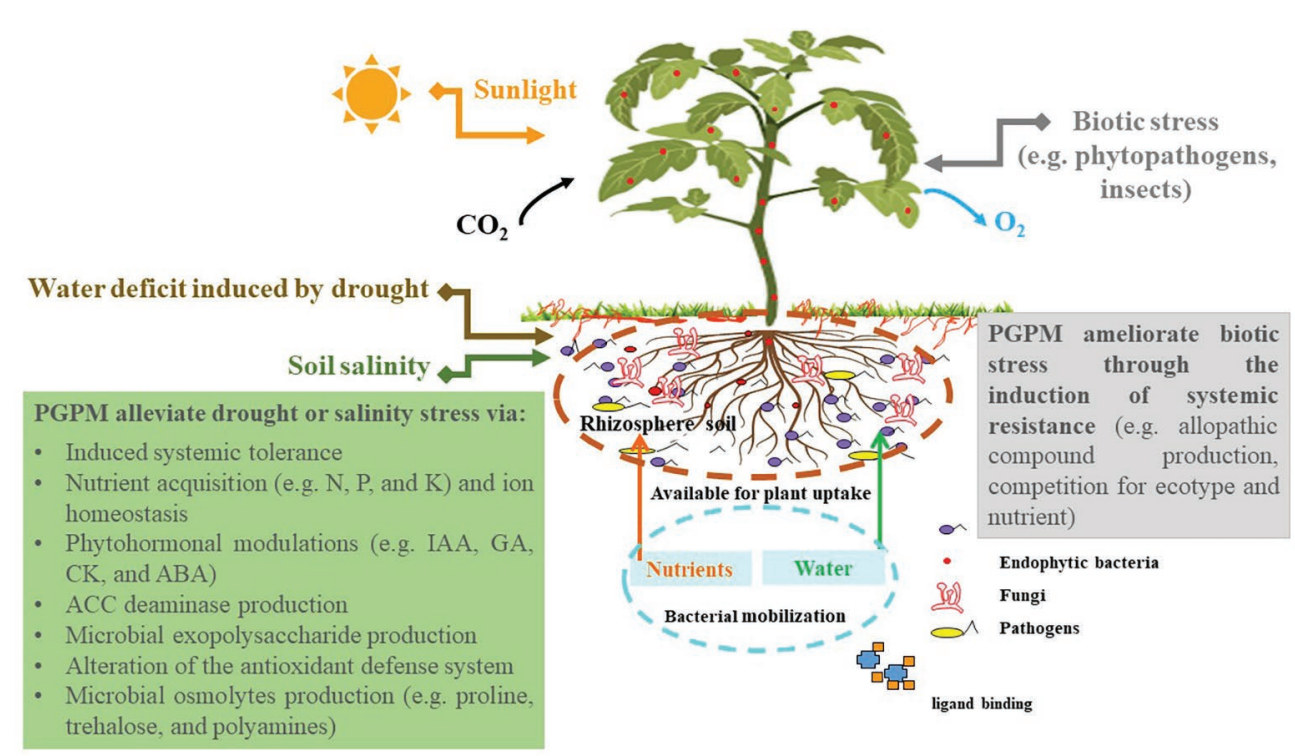

FIGURE 2 | Plant-plant growth-promoting microorganism (PGPM) interactions confer abiotic stress tolerance. PGPM, plant growth-promoting microorganisms; IAA, indole-3-acetic acid; GA, gibberellins; CK, cytokinins; ABA, abscisic acid; ACC, 1-amino-cyclopropane-1-carboxylic acid; N, nitrogen; P, phosphate; K, potassium. 


\section{Chlorophyll Content}

Photosynthetic pigments are essential for light harvesting and, hence, for photosynthesis and plant growth. The decrease in chlorophyll content under drought or salinity stress, caused by pigment photooxidation and chlorophyll degradation, is considered a symptom of oxidative stress. Drought and salinity have been found to induce a reduction in chlorophyll contents in leaves of various crops, such as Carthamus tinctorius (Siddiqi et al., 2009), Phaseolus vulgaris (Beinsan et al., 2003), Vigna subterranean (Taffouo et al., 2010) and P. vulgaris (Taïbi et al., 2016), indicating the process of photooxidation (Rahdari et al., 2012). The reduced chlorophyll contents under drought or salinity stress may trigger the inactivation of photosynthesis. Moreover, drought or salinity induced reduction in chlorophyll content is contributed to excessive chloroplast swelling, loss of chloroplast membranes, the appearance/development of intracellular lipid droplet, and distortion of lamellae vesiculation (Kaiser et al., 1981). Low photosynthetic pigment content may hamper photosynthetic potential and thus primary plant production.

\section{Phytohormonal Regulation}

Plant stress response mechanisms are highly complex comprising the integration of several pathways. The perception of a stress event starts signal transduction cascades that interact with pathways traduced by phytohormones (Harrison, 2012). Endogenous phytohormones are not only important growth regulators but also play a pivotal role in plant adaptation to drought and salt stress by modulating plant physiology and molecular responses (Fahad et al., 2015; Wani et al., 2016). Water deficit and salt stress may alter the biosynthesis, accumulation, and distribution of several phytohormones, including ABA, jasmonic acid (JA), salicylic acid (SA), indole-3-acetic acid (IAA), gibberellins (GA), and cytokinins (CK), therefore, promoting specific protective mechanisms (Eyidogan et al., 2012).

Abscisic acid is one of the most important phytohormones and the major stress-responsive hormone produced after signal perception by drought and salt stress (Fahad et al., 2015; Ullah et al., 2018). Stress perception triggers the synthesis of $A B A$ predominantly in roots (however ABA can also be synthesized in leaf cells and translocated around the plant) and acts in the regulation of the stomatal aperture, channel activities, and in the expression of ABA-responsive genes (Ullah et al., 2018). In leaves, $\mathrm{ABA}$ increases after drought or salt stress and regulates stomatal aperture (promote stomatal closure), consequently helping plants to control the water status and preventing dehydration. For instance, as a result of drought, leaf mesophyll cells come to be dehydrated, causing a release of ABA. The amount of $\mathrm{ABA}$ is then stored in the chloroplasts of guard cells. The increased concentration of ABA triggers the efflux of potassium $(\mathrm{K})$ and calcium from the guard cells, leading to stomatal closure with water loss in the guard cells. The shortage of water causes discoloration, a decrease in the rate of photosynthesis in plants, and an increase in leaf trichomes and stomata on the leaf surface. Besides, $\mathrm{ABA}$ increases the production of ROS (especially $\mathrm{H}_{2} \mathrm{O}_{2}$ ) in guard cells to decrease the stomatal aperture (stomata closure; Golldack et al., 2014;
Mittler and Blumwald, 2015). Furthermore, ABA is also involved in root architectural modifications by promoting root elongation to reach deep water in the soil during water deficit conditions and can upregulate the synthesis of osmoprotectants (e.g., proline), antioxidant enzymes, and the expression of several drought and salt stress-responsive genes and proteins (e.g., late embryogenesis abundant proteins and dehydrins; Comas et al., 2013; Fahad et al., 2015; Mittler and Blumwald, 2015; Wani et al., 2016; Ullah et al., 2018). Some works also demonstrated that $\mathrm{ABA}$ induces modification of primary lipid metabolism, contributing to stress adaptive reorganization of membranes (e.g., change the monogalactosyldiacylglycerol and digalactosyldiacylglycerol contents in the chloroplast envelope and thylakoid membranes) and to the maintenance of cellular energy supply under drought and salt stress (Golldack et al., 2014).

Jasmonic acid and its derivatives, the jasmonates, besides being involved in reproductive processes, root growth, and fruit ripening, also play a crucial role in drought and salt stress response regulation in plants (Fahad et al., 2015; Wani et al., 2016). Biosynthesis of JA occurs usually in leaves, particularly in chloroplasts and peroxisomes (Cheong and Choi, 2003), despite some reports also refer to the roots as a synthesis organ of this hormone (Fahad et al., 2015). Similar to ABA, JA induces drought and salinity tolerance in plants in various ways, such as inducing stomatal closure, scavenging of ROS, and promoting root development. Walia et al. (2007) proposed that JA induced salinity tolerance by regulating arginine decarboxylase, RuBisCO activase, and apoplastic invertase.

Salicylic acid is a naturally occurring phenolic compound, which is usually involved in the regulation of pathogen-associated protein expression (Miura and Tada, 2014). Besides, several works demonstrated that SA also has an important role in plant defense against drought and salt stresses (Khodary, 2004; Fahad and Bano, 2012; Miura et al., 2013). Low concentrations of SA enhance the antioxidant capacity of plants, but high concentrations can cause cell death or even some susceptibility to abiotic stresses (Jumali et al., 2011). SA activates the expression of genes involved in the biosynthesis of secondary metabolites, chaperones, and heat shock proteins (Miura and Tada, 2014). SA biosynthesis takes place mostly in the chloroplasts being then transported to other parts of the plant.

Indole-3-acetic acid is widely acknowledged for its implications in plant growth and development (e.g., cell elongation, vascular tissue development, and apical dominance; Fahad et al., 2015). Also, during water deficit and salt stress, this phytohormone seems to coordinate growth (Eyidogan et al., 2012; Iqbal et al., 2014) and induce the expression of genes related to root meristem initiation, promoting root branching and increasing plant stress tolerance (Wolters and Jürgens, 2009).

\section{Osmotic Adjustment}

Osmotic adjustment (OA), defined as the lowering osmotic potential as a result of net solute accumulation in response to water stress, is well known to have a significant role in plant adaptation to dehydration via the maintenance of turgor pressure, relative water content, stomatal conductance, and 
specific cellular functions (Martínez et al., 2004). The accumulation of compatible solutes in plants is thought to benefit stressed cells either by acting as cytoplasmic osmolytes to facilitate water uptake and retention, or by protecting macromolecules (e.g., proteins, chloroplast, and membranes) and their structure from stress-induced damage (Martínez et al., 2004). It is well known that plant growth is inhibited by drought before photosynthesis, causing the release of sugars toward OA. Moreover, OA can sustain photosynthesis by maintaining turgor as stress develops. Therefore, OA inhibits plant growth and protects photosynthesis simultaneously. Moreover, as one of the most important physiological parameters of plant adaptation to drought, cell wall elasticity (CWE) plays a key role in turgor regulation. The increases in CWE have been found in several plant species when they respond to drought, which may contribute to maintaining cell turgor or symplast volume (Marshall and Dumbroff, 1999). Under osmotic stress, plants can avoid reduced water potential and sustain turgor by decreasing their turgor-loss volume via shrinkage associated with cell wall elastic adjustment (Marshall et al., 1999). Cell shrinkage/contraction (a reduction in cell size) has been considered as the main character involved in plant resistance to drought stress. For instance, Alves and Setter (2004) have found a reduction in cell size and osmolyte accumulation in Manihot esculenta grown under drought stress.

Plants generally respond to salinity stress using different mechanisms, depending on the severity and duration of the stress. Soil salinity initially hinders plant growth in the form of osmotic stress (hyperosmotic stress) followed by ion toxicity (hyperionic stress; Munns and Tester, 2008). During the initial phase of salinity stress, root water absorption capacity diminishes, and the leaf water loss is augmented because of salt-induced osmotic stress in plants. This hyperosmotic stress results in various physiological alterations in plants, such as membrane disruption, nutrient imbalance, ROS detoxification, antioxidant enzyme activity, and photosynthetic activity. The latter phase is a hyperionic stress due to $\mathrm{Na}^{+}$and $\mathrm{Cl}^{-}$uptake and their subsequent accumulation in leaves, leading to nutritional imbalance (e.g., inhibition of $\mathrm{K}^{+}$uptake) and physiological disorder (e.g., significant alterations in the metabolism; Munns and Tester, 2008). It is well known that the accumulations and functions of compatible solutes, such as soluble sugars, proline, glycine betaine, and sugar alcohols, play an essential role in OA. The distribution of photoassimilates between source and sink tissues can contribute to accumulating these solutes (Hare et al., 1998). However, the role of these solutes in OA under salinity stress is still under debate. In many plant species, the absolute osmolyte concentrations are doubtful to mediate OA. However, these solutes have beneficial potential to buffer cellular redox potential, protect the cellular structure, and adaptively modify carbon allocation and sugar metabolism under salt stress. For instance, Suwa et al. (2008) observed a decrease in carbon allocation toward the roots of Lycopersicon esculentum, even before the salt symptoms of reduced photosynthesis. As a result of such changes in carbon distribution, the accumulation of sugar in mature leaves is higher under salt stress. The changes in sugar homeostasis and metabolism have been found in plants under salt stress (Peng et al., 2016). These changes are associated with cell wall modification by either stiffening cell walls to reduce the salt entry or enhancing cell wall elasticity to maintain cell turgor (Gall et al., 2015). However, sugar transport and homeostasis as well as cell wall viscoelastic properties are tightly regulated during plant development. Therefore, alterations in plant susceptibility to salt stress are possible, and they are determined by carbon status (Wingler, 2017).

\section{Source/Sink Dynamics}

In general, carbon assimilation is performed by source organs (exporters of photoassimilates, e.g., fully developed leaves), which converts it into glucose and other sugars and then exports them to sink organs (importers of fixed carbon, e.g., roots, stems, fruits, and seeds) for plant organ growth (Yu et al., 2015). During plant growth, communication between source organs and sink organs plays an important role in carbohydrate assimilation and partitioning/allocation that are strictly connected to photosynthesis. Carbohydrates, the end product of photosynthesis, after being exported from the leaves to non-photosynthetic tissues provide the substrate for growth and cell maintenance. Sugar transporters are required for carbohydrate allocation to long-distance at the plant level and a short distance in sugar partitioning at the cellular level. Source-to-sink transport of sugar has been considered as the main factor affecting plant growth and it depends on the proficient and controlled distribution of sugars across plant organs via the phloem. Nevertheless, sugar transport via the phloem can be influenced by various environmental stresses at three diffident levels (namely the source, the sink, and the path between source and sink) that may change source/sink relationships (Lemoine et al., 2013).

Under drought or salt conditions, the reduction of global photosynthetic productivity can be aggravated, therefore, impacting the carbon flow to different sink organs (Courtois et al., 2000; Lebon et al., 2006; Penella et al., 2016). The impact of drought and salinity on sugar metabolism and phloem loading has been widely investigated (Burke, 2007; Hummel et al., 2010; Lemoine et al., 2013). In sucrose-translocating species, carbohydrate levels in leaves and source-to-sink translocation patterns are generally altered by drought or salinity stress as the result of reduced photosynthesis (Pattanagul and Thitisaksakul, 2008). Sucrose and hexose accumulations contribute significantly to osmotic modulation to sustain metabolic activity in source leaves. However, the concentration of sugars may increase in leaves due to reduced demand as a consequence of growth limitation.

Under drought stress, transcript abundance of several genes encoding gluconeogenic enzymes including fructose biphosphate aldolase (Cramer et al., 2007), hexokinase in phosphorylation of soluble sugars (Whittaker et al., 2001), and galactinol synthase in raffinose family oligosaccharide biosynthesis (Taji et al., 2002) increased in source leaves. Moreover, drought may also cause changes in the concentrations of organic nutrients (e.g., sugars and amino acids). In sink organs, the presence of drought stress 
can promote sucrose biosynthesis rather than starch biosynthesis by inducing sucrose-phosphate synthase and hindering ADP glucose pyrophosphorylase (Geigenberger et al., 1997). At different development stages, drought may induce senescence and increase reserve mobilization, which is considered as a component of basic strategies for plant development and stress alleviation (Chandlee, 2001). In general, drought can cause higher sugar content in the cytosol to lower osmotic potential, therefore, maintaining cell turgor (Razavi et al., 2011). This would eventually diminish photosynthetic actives and thus accelerate senescence in leaves. The drought-induced increase in sugar levels in plants may be due to the attempt of plants to adjust their metabolism to maintain the osmotic homeostasis (Giné-Bordonaba and Terry, 2016). Sugar concentrations may affect leaf development via senescence as direct causal signals, and as substrates for $\mathrm{C}$ mobilization and reallocation to help host plants mitigate the negative effects of drought (Cramer et al., 2007).

Salinity stress generally results from irrigation with poor quality water and it shares many similar features with drought stress, particularly in the early stress response, as the primary effect induced by both stresses inhibits the absorption of water through the root system due to the osmotic effect (Navarro et al., 2008). However, the long-term plant responses to both stresses may behave differently, because sodium toxicity can add to the initial stress due to its transport within plant tissues via the transpiration stream. The $\mathrm{K}^{+}$channels are involved in the $\mathrm{Na}^{+}$recirculation from leaf phloem to roots for exertion, thus diminishing the amount of $\mathrm{Na}^{+}$in leaves (Berthomieu et al., 2003). There is a lack of information about the positive impact of salinity on sucrose translocation into the phloem. As discussed above, salinity stress can adversely affect photosynthesis, thus leading to plant growth impairment, especially leaves (Suwa et al., 2006). In the study of Lohaus et al. (2000), salinity did not change sucrose concentration in the phloem of $Z$. mays, whereas increased amino acid and $\mathrm{Na}^{+}$ concentration in the sieve tube sap. The increased root/shoot ratio was probably attributed to the fact that the higher amount of amino acids was transported to the roots. Dissimilarly, Suwa et al. (2008) found that salinity stress inhibited phloem sucrose uptake and translocation, causing the insufficient distribution of sucrose to the roots. Some salt-tolerant plant species do not tolerate drought stress and vice versa (Kefu et al., 2003). The specific mechanisms that plants use for salt stress alleviation are either by minimizing the entry of salt ions into plant tissues or reducing the salt concentrations in the cell cytoplasm. In general, halophytes (plants that tolerate high concentration of salt) can exclude most of the $\mathrm{Na}^{+}$and $\mathrm{Cl}^{-}$into the soil solution and compartmentalize salts in cell vacuoles, therefore, achieving salt tolerance, whereas most of the glycophytes (plants that tolerate relatively low concentration of salt) have a low potential to exclude salt and, therefore, accumulate toxic ions in the leaves with the transpiration flow (Munns, 2002).

Besides, polyols are thought to be the major osmotically active and antioxidant molecules for plants to cope with stress (Stoop et al., 1996). When plants are exposed to salinity stress, the polyol concentration usually increases in different plant tissues. This is probably the reason why salinity resistance/tolerance is commonly found in polyol synthesizing plants. Furthermore, the increased polyol synthesis together with an increased expression of genes encoding polyol transporters was observed in the phloem of Plantago major (Pommerrenig et al., 2007), Apium graveolens (Landouar-Arsivaud et al., 2011), and Olea europaea (Conde et al., 2011), suggesting that long-distance polyol transport is induced/enhanced by salinity stress. The translocation of polyols from shoots to roots may positively affect root metabolism and water potential.

\section{Antioxidants}

Both drought and salinity can induce the formation of ROS such as superoxide, singlet oxygen, hydrogen peroxide, and hydroxyl radicals within plant cells, and their overaccumulation results in oxidative damage of membrane lipids, proteins, DNA, and nucleic acids in plants (Gill and Tuteja, 2010). To scavenge high levels of ROS, the efficient non-enzymatic (e.g., ascorbate, flavonoids, glutathione, tocopherols, and phenolics) and enzymatic [e.g., catalase (CAT), peroxidase (POD), ascorbate peroxidase (APX), and superoxide dismutase (SOD)] antioxidant defenses system is involved. The upregulation of antioxidants has been found in drought or salinity tolerant cultivars of various crops, such as Calendula officinalis, Solanum lycopersicum, Jatropha curcas, and Z. mays (Chaparzadeh et al., 2004; Mittova et al., 2004; Gao et al., 2008; Anjum et al., 2017), implying the great potential of antioxidants to ameliorate drought/saltinduced oxidative stress. Maintaining a high level of antioxidative enzyme activities contributes greatly to drought or salt stress alleviation by enhancing the capacity of host plants against oxidative damage. Therefore, the ability of antioxidant enzymes to scavenge ROS and diminish the damaging impacts are closely related to plant drought or salinity stress resistance. Besides, drought or salinity can adversely affect various subcellular compartments (e.g., vacuole, cytoplasm, and nucleus), cell organs, and whole plant level (Rahdari et al., 2012), consequently affecting plant biomass and health. Thus, the alleviation of drought and salinity stresses is important to achieve a healthier food growing environment.

\section{METABOLIC RESPONSES TO DROUGHT AND SALINITY STRESS}

Stress conditions strongly affect plant metabolism, resulting in deep modifications in metabolites biosynthesis, transport, and storage (Fraire-Velázquez and Balderas-Hernández, 2013; Di Ferdinando et al., 2014). A quick metabolic response at the beginning of the stress event helps the plant to restore its performance faster and is crucial to stress acclimation and further plant survival (Fraire-Velázquez and Balderas-Hernández, 2013).

Metabolomic studies can help to identify key stress metabolite that could be useful as indicators of the adaptability of plants/ species to drought or salinity, to detect the adjustments of groups of compounds involved in mediating the stress tolerance, and to investigate the flexibility of a species to rearrange principal metabolic pathways (such as carbon and nitrogen metabolism) 
to tolerate and/or adapt to various stresses (Jorge and António, 2018). Within the metabolic changes, both primary (e.g., osmolytes) and secondary (e.g., defense compounds) metabolic adjustment have been reported. Primary metabolites are essential for plant growth and development, being more conserved in their abundance within species, while secondary metabolites (besides it is not necessary for survival) play a role in the interaction of the plants with their environment and, therefore, differ more across the species (Jorge and António, 2018).

Under drought conditions, the adjustment of photosynthesis and osmoregulation is one of the earliest plant strategies (Slama et al., 2015). Metabolomic studies identified the accumulation of osmolytes, such as some carbohydrates (e.g., glucose, sucrose, trehalose, and raffinose), polyols (e.g., mannitol and sorbitol), amino acids (e.g., proline, betaine, valine, leucine, and isoleucine), quaternary ammonium compounds (e.g., glycine betaine, $b$-alanine betaine, and proline betaine), and polyamines (e.g., putrescine, spermidine, and spermine), which have an important role in the decrease of the osmotic potential and maintenance of cell turgor pressure (as the cell uptakes water), and contribute to the stabilization of membranes, enzymes, and proteins (Jorge and António, 2018; Sharma et al., 2019). Also, the accumulation of osmolytes helps to control ROS levels, provides energy to cope with stress, contributes to repair processes, and supports further growth (Silva et al., 2018; Fàbregas and Fernie, 2019). Other metabolites related to the tricarboxylic acid (TCA) cycle were identified in several metabolomics studies, but these compounds respond more heterogeneously to drought. For example, several reports revealed contrasting results, describing increases of TCA acids (e.g., isocitrate, oxoglutarate, succinate, fumarate, and malate) in Arabidopsis (Fàbregas et al., 2018), while in rice, showed decreased levels (Todaka et al., 2017). TCA cycle metabolites provide the precursors for energy generation and are also an integral part of the oxidative defense machinery (Mailloux et al., 2007). The overproduction of ROS is one of the primary consequences of the impairment of photosynthesis under drought conditions, and some TCA cycle compounds, such as $\alpha$-ketoglutarate, participate in the detoxification of ROS (Fàbregas and Fernie, 2019). Besides, drought also upregulates the biosynthesis of other antioxidant compounds, leading to the accumulation of ascorbate, glutathione, and several polyphenols (Das and Roychoudhury, 2014). Among plant defense metabolites, the polyphenols with ROS scavenger capacity (e.g., anthocyanins, 4-coumaric acid, caffeic acid, ferulic acid, cis-resveratrol-3-O-glucoside, trans-resveratrol-3$O$-glucoside, catechin, epicatechin, caftaric acid, kaempferol and kaempferol-3-O-glucoside, cyanidin-3-O-glucoside, rutin, quercetin and quercetin-3-O-glucoside, luteolin and luteolin7-O-glycoside, and apigenin and chlorogenic acid) were the most responsive to drought (Di Ferdinando et al., 2014; Sharma et al., 2019). For instance, the rapid accumulation of the anthocyanins and flavones may act as vacuole ROS scavengers in response to drought (Fàbregas and Fernie, 2019). Also, other flavonoids like kaempferol and quercetin were enhanced by drought, participating efficiently in the detoxification of $\mathrm{H}_{2} \mathrm{O}_{2}$ molecules (Sharma et al., 2019). Lipophilic compounds are also sensitive to drought. The compounds involved in stress detoxification and tolerance, such as 2-naphthalene methanol, heneicosane, caryophyllene oxide, heptadecanal, tetratetracontane, heptatriacotanol, tetracosane, 1-heptacosanol, phytol, n-nonadecanol-1, n-pentadecanol, octacosyl acetate, octadecanoic acid, and hexatriacontane, increased significantly in response to water deficit (Soliman et al., 2019).

Under salinity, osmotic stress affects cell functions, leading to cell damages and a slowdown of plant growth. Sodium accumulation in cells induces secondary stress that affects negatively some principal processes, such as protein biosynthesis, photosynthesis as well as potassium ion absorption (Deinlein et al., 2014). Metabolite responses to salt stress have much in common with drought, evidencing an overlapping of biochemical pathways and similar metabolite adjustments. For instance, the accumulation of osmolytes is also an important adaptive mechanism to salinity, enabling cell turgor maintenance, and reposition of water status, membrane stabilization, and ROS increase control (Kao, 2015). Several metabolomic studies revealed that salt stress induces the accumulation of few primary metabolites, such as proline or primary products in the $\mathrm{N}$ metabolism (such as allantoin, urea, and glutamine; Slama et al., 2015). Also, some carbohydrates, such as sucrose, tagatose, psicose, glucoheptose, idose, allose, talose, lactulose, and cellobiose, and the sugar alcohol (inositol) respond with a sharp increase under salinity. Salt stress induces an overaccumulation of ROS (e.g., superoxide anions, hydroxyl ions, and hydrogen peroxide), resulting in damages in membranes and macromolecules (Sharma et al., 2019). The phenolic compounds have an important role in acting as powerful antioxidants that help in scavenging ROS. Metabolomic studies revealed that the phenylpropanoid biosynthetic pathway is one of the most stimulated by salinity. The stimulation of this pathway results in the increased production of various phenolic compounds, such as hydroxybenzoic acids (e.g., gallic acid, vanillic acid, syringic acid, p-hydroxybenzoic acid, and ellagic acid), hydroxycinnamic acids (e.g., caffeic acid, chlorogenic acid, $p$-coumaric acid, $m$-coumaric acid, ferulic acid, sinapic acid, and trans-cinnamic acid), and flavonoids (e.g., quercetin and iso-quercetin, rutin, luteolin and luteolin-7-O-glycoside, apigenin, kaempferol, and luteolin; Sharma et al., 2019). Accumulation of lipophilic compounds, such as $\alpha$-tocopherol implicated in antioxidant responses (e.g., oxygen free radical, lipid peroxyl radicals, and ${ }^{1} \mathrm{O}_{2}-$ scavenging capacity) in different species were found to activate the resistance to salinity (Malik et al., 2013). Carotenoids, another group of lipophilic antioxidants that can remove several types of ROS, were found to accumulate in sugar cane under salt stress (Malik et al., 2013).

In general, drought and salinity alter several metabolic pathways. However, some of them are not well studied and the potential of these metabolic changes is not completely and scientifically explored. Therefore, it is important to understand better, for instance, how controlled stress situations (e.g., low or moderate water deficit) shifts metabolic pathways resulting in the enhancement of metabolites that, besides protecting plants, can also alter its nutritional value. For instance, the 
increase of some metabolites, such as $\beta$-carotene in Brassica chinensis var. parachinensis, vitamin C in S. lycopersicum, polyphenols in Fagopyrum esculentum, stevioside in Stevia rebaudiana leaves, allicin in Allium sativum, and rosmarinic acid in Salvia miltiorrhiza leaves, in response to water deficit (Sarker and Oba, 2018; Isah, 2019) enhance the quality of these species/fruits. Moreover, the implications of these metabolic changes in plant growth and productivity must also be taken into consideration.

\section{PLANT-MICROBE INTERACTIONS CONFER ABIOTIC STRESS TOLERANCE}

Plant-microbe interactions are considered as an essential determinant of ecosystem processes (Cheng et al., 2019). Plants are living intimately with the microbial communities in the root system (Friesen et al., 2011). In general, the roots shape the niche or environment where the microbial communities establish and survive, while the plant-associated microbes, especially plant growth-promoting microorganisms (PGPM) can affect the growth, nutritional status, development, and fitness of the host plants (Pascale et al., 2020).

\section{Role of PGPM in Abiotic Stress}

Plant growth-promoting microorganisms including plant growth-promoting bacteria (PGPB), rhizobia, and arbuscular mycorrhizal fungi (AMF) are defined as microbes inhabiting around/in free-living soils, rhizosphere/rhizoplane (e.g., rhizobacteria and ectomycorrhizal fungi), or tissue interior (e.g., endophytic bacteria, endomycorrhizal fungi, and AMF) that are beneficial for plants (Ma et al., 2011). The role of PGPM in plant growth, nutrient acquisition, and biocontrol activity has been well established. Despite the difference between these types of microbes, these PGPM strains can colonize the rhizosphere soils or endo-rhizosphere of plants and they can protect plants from both abiotic (e.g., drought, salinity, and extreme temperature) and biotic stresses (e.g., phytopathogens) and enhance plant establishment and growth via the same plant growth-promoting mechanisms that involve direct and indirect mechanisms (Ma et al., 2019b). In general, the direct mechanisms include the facilitation of nutrient acquisition (e.g., nitrogen fixation, siderophore sequestration, and potassium and phosphate solubilization; Kohler et al., 2009), synthesis of phytohormones (e.g., auxin, cytokinin, ABA, and GA; Ma et al., 2019a), exopolysaccharides (EPS; Naseem et al., 2018), and volatile or non-volatile compounds, as well as induction of ACC deaminase (Forni et al., 2017). Indirect mechanisms include biological control against phytopathogens (e.g., bacteria, fungi, and nematodes) through the synthesis of allelochemicals (e.g., antibiotics and antifungal metabolites) or induced systemic resistance (e.g., reinforcement of plant cell wall, production of antimicrobial substances, and the synthesis of pathogen-related proteins; Ma et al., 2011). As the abiotic stresses (drought and salinity) have adverse impacts on crop yields, the potential role of PGPM in improving plant performance makes it important to elucidate the responses of plant-associated microbes to environmental change (Compant et al., 2010).

\section{Drought and Salinity Stress Microbial Ecology}

Drought or salinity could significantly reduce plant yields, cause land degradation, and influence plant-microbe interactions (Munns, 2002; Lesk et al., 2016). Recently, Santos-Medellín et al. (2017) explored the responses of rice root-associated microbiomes to drought stress and they found major compositional changes in the rhizosphere and endosphere communities, particularly changes in the relative abundance of taxonomically diverse bacteria in response to drought. Drought-resistant PGPM might potentially benefit the host plants and improve their adaption to various abiotic stresses, due to their contribution to plant tolerance to drought and their ability to protect plants from infection by pathogens ( $\mathrm{Ma}$ et al., 2016, 2017; Tiepo et al., 2018; Eke et al., 2019; Halo et al., 2020). The isolation, characterization, and identification of microbes possessing the ability to promote plant tolerance to drought might be used to alleviate crop losses under adverse climate change conditions. Likewise, Xu et al. (2018) demonstrated that drought greatly diminished bacteria community diversity in the rhizosphere and root endosphere, and increased the abundance of Actinobacteria and Firmicutes, which were most pronounced in the root endosphere. Besides, drought stress resulted in a shift in the metabolites secreted by the roots of host plants. The findings suggest that there are molecular dialogs/interactions between host plants and their associated microbes for reshaping rhizosphere biota to cope with/adapt to drought stress. Unraveling the molecular dialogs may advance fundamental knowledge of employing beneficial microbes to improve plant stress tolerance. However, there is a lack of information about whether and how the drought-enriched metabolites deploy/drive rhizosphere microbial composition.

So far, the root microbial structure, composition, and function under natural and agricultural environments have been extensively explored. However, there has been no coordinated effort to dissect the impacts of extreme environments (e.g., drought, salinity, and heat) on microbial community composition for helping understand the mechanisms of reshaping plant-microbe interactions under changing climatic conditions (Busby et al., 2017). Also, the identification of rhizosphere microorganisms that thrive under different adverse environmental conditions can result in the discovery of beneficial symbiosis, as the microbial traits that confer stress tolerance may be beneficial to the plant hosts (Rodriguez et al., 2008). By the end of this century, the frequency of drought is expected to increase, and this trend may gradually change the underground characteristics of the affected agricultural ecosystems. Although drought may reconstruct the soil bacterial diversity (Barnard et al., 2013; Bouskill et al., 2013), little is known about the impact of drought on microbial communities in the rhizosphere of various plant species. These microbial communities might be directly affected by drought stress and/or indirectly by host-mediated processes since drought triggers a series of plant molecular, physiological, and developmental responses (Xu et al., 2010; Gray and Brady, 2016). 
Salinity stress is known to influence both bacterial and fungal diversity in different manners, by driving the soil nutrient cycle in various land ecosystems. In general, bacterial diversity decreases with salinity, whereas the response of fungi to this stress is more complex. Bacterial and fungal community structure depends on the levels of salinity (Thiem et al., 2018). Zhang et al. (2019a) reported that the increasing soil salinity decreased the relative abundances of soil bacterial, fungal, and arbuscular mycorrhizal communities and, thereafter, affected their function (e.g., organic matter decomposition and lignin degradation) in saline coastal ecosystems.

\section{Mechanisms of PGPM Mediated Drought and Salinity Tolerance}

Several strategies have been explored to alleviate the toxic/ detrimental effects induced by abiotic stress on plant growth and development, including plant genetic engineering, and recently the application of PGPM (Dimkpa et al., 2009; Ma et al., 2016, 2017, 2019a,b). Although Yang et al. (2009) and Dodd and Perez-Alfocea (2012) have extensively reviewed the use of PGPB in plants as elicitors of tolerance to abiotic stresses, we attempt to shed light on the underlying mechanisms used in various PGPM species to assist crops to cope with drought and salinity stresses. As the basic mechanisms behind drought and salinity stresses are similar, they are discussed together under common headings (Figure 3).

\section{Microbial Induction of Systemic Resistance}

Plant growth-promoting microorganisms induced systemic tolerance (IST) may lead to physical and chemicals changes in plants, thus contributing to plant tolerance to abiotic and biotic stresses. Many researchers have advocated that crops inoculated PGPM persuade morphological and biochemical changes resulting in increased drought tolerance by eliciting IST (Yang et al., 2009; Ma et al., 2016, 2017; Vurukonda et al., 2016).
Facultative endosymbionts can confer adaptive advantages to their hosts, such as digestion, fecundity, and resistance to abiotic (e.g., drought, salinity, and heat) or biotic stresses (Guo et al., 2017). IST is accompanied by PGPM by allopathic compound production, competition for ecotype and nutrient. Allelochemicals comprising antibiotics, lytic enzymes, and siderophores, act effectively against pathogens and suppress their growth (Jain et al., 2013). Frago et al. (2017) demonstrated that Hamiltonella defensa, an endosymbiont of aphids and other sap-feeding insects, protected plants against parasitoids and diminished the emission of plant defensive volatiles following aphid attack.

\section{Nutrient Acquisition and Ion Homeostasis}

Plant growth-promoting microorganisms have a great capacity to convert nutritional elements from unavailable to available form through biological processes (Ma et al., 2011). Their performances are greatly influenced by various environmental factors, such as soil type and properties, metal contamination, and abiotic stress (e.g., drought and salinity). Egamberdiyeva (2007) found that three PGPB isolates Pseudomona alcaligenes PsA15, Bacillus polymyxa BcP26, and Mycobacterium phlei MbP18 could tolerate high temperatures and salt concentrations and have stimulatory effects on nitrogen, phosphorus, and potassium uptake of $Z$. mays in nutrient-deficient calcisol soil, thus enhancing the ability of the plant to survive in arid and saline soils. Under drought stress, mycorrhizal association with the plants can improve nutrient accumulation via the establishment of extensive hyphal networks and glomalin secretion that facilitate water and nutrient uptake (Bahadur et al., 2019).

It is well known that salinity inhibits plant growth owning to increased $\mathrm{Na}^{+}$concentration and low $\mathrm{K}^{+} / \mathrm{Na}^{+}$ratio in plants. A number of studies have demonstrated that PGPM inoculation avoided the over-accumulation of $\mathrm{Na}^{+}$and maintained the ion homeostasis under salinity stress (Bharti et al., 2014; Tewari and Arora, 2014). Kohler et al. (2009) examined the effects

\begin{abstract}
Initially induce plant adaptation to these stressors, but with severe level, they can damage plants

DS \& SS: plant responses vary in morphology, physiology, biochemistry, and metabolism
\end{abstract}

Reduce plant growth, yield and change root morphology

DS \& SS: cell dehydration, inhibition of cell growth

Photosynthesis inhibition and
oxidative stress
DS \& SS: stomatal closure and
reduction of the intercellular $\mathrm{CO}_{2}$
concentration, loss of membrane
integrity and up-regulation of
antioxidants

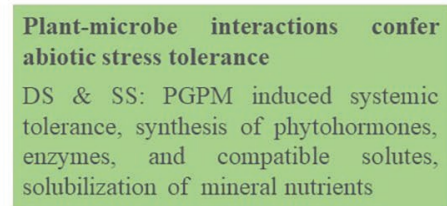

Metabolic responses

DS \& SS: modify the biosynthesis, transport, and storage of metabolites (e.g. osmolytes and defense compounds)

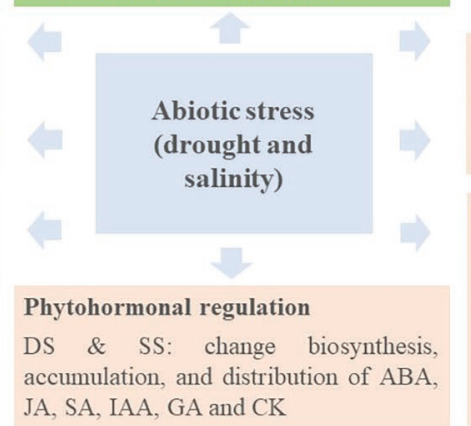

Osmotic imbalance
DS: induces hyperosmotic stress
SS: induces hyperosmotic stress
followed by hyperionic stress
Source/sink dynamics
DS: promotes sucrose biosynthesis
to lower osmotic potential, thus
maintaining cell turgor.
SS: has no effect or negative effect
on phloem sucrose uptake and
translocation

FIGURE 3 | Mechanisms underlying abiotic stress response and adaptation. DS, drought stress; SS, salinity stress; PGPM, plant growth-promoting microorganisms; ABA, abscisic acid; JA, jasmonates; SA, salicylates; IAA, indole-3-acetic acid; GA, gibberellins; CK, cytokinins. 
of inoculation of plant growth-promoting rhizobacterium Pseudomonas mendocina, alone or in combination with AMF Glomus intraradices or Glomus mosseae on the growth, nutrient accumulation, and physiological parameters of Lactuca sativa exposed to salt stress. The results showed that L. sativa inoculated with $P$. mendocina reduced plant $\mathrm{Na}^{+}$uptake and increased $\mathrm{K}^{+}$uptake, resulting in a higher $\mathrm{K}^{+} / \mathrm{Na}^{+}$ratio, as well as greater shoot biomass, compared to the control treatments, suggesting that the application of PGPB could be used to alleviate salinity stress in plants that are sensitive to salt. The volatile organic compounds synthesized from Bacillus subtilis decreased transcriptional expression of a high-affinity $\mathrm{K}^{+}$transporter (HKT1) in Arabidopsis roots whereas it was upregulated in shoots, thus reducing $\mathrm{Na}^{+}$uptake by roots and $\mathrm{Na}^{+}$expulsion from shoots (Zhang et al., 2008).

\section{Phytohormonal Modulations}

Plant growth-promoting bacteria can produce phytohormones such as IAA, GA, ABA, etc., which stimulate plant cell growth and division to become tolerant/resistant to environmental stresses (Ma et al., 2019a). Synthesis of IAA and GA by PGPB caused an increase in plant growth (e.g., root length, root surface area, and the number of root tips) and nutrient uptake, thus ameliorating plant health under drought and salinity stress (Egamberdieva and Kucharova, 2009; Ma et al., 2016, 2017). Several studies have found that PGPB can improve the growth of various plant species (such as S. lycopersicum, Solanum pimpinellifolium, Capsicum annuum, B. napus, Helianthus annuus, P. vulgaris, T. aestivum, and L. sativa) under drought or saline conditions (Yildirim and Taylor, 2005; Barassi et al., 2006; Hussain et al., 2014; Ma et al., 2016, 2017, 2019a; Khan et al., 2017).

The abscisic acid produced by PGPB can also contribute to microbe-induced drought or salinity tolerance. PGPB Phyllobacterium brassicacearum STM196 improved osmotic stress tolerance in Arabidopsis thaliana by increasing ABA content, thus inducing a reduction in leaf transpiration (Bresson et al., 2013). Likewise, inoculation of cytokinin producing PGPB B. subtilis enhanced the ABA content in the shoots of Platycladus orientalis seedlings and the stomatal conductance, consequently conferring drought stress tolerance (Liu et al., 2013). In terms of salinity stress, Naz et al. (2009) found that the bacterial strains isolated from Khewra exhibited salt tolerance and were able to produce IAA, GA, trans-zeatin riboside, and ABA. Moreover, the inoculation of these strains greatly improved the growth and proline contents in Glycine max under salt stress. Similarly, inoculation of ABA-producing endophytic bacteria significantly enhanced salinity stress tolerance in O. sativa by modulating endogenous hormone and upregulating essential amino acids (e.g., glutamic acid, aspartic acid, phenylalanine, proline, and cysteine; Shahzad et al., 2017). Sadeghi et al. (2012) observed that inoculation of IAA and siderophore producing Streptomyces isolate significantly enhanced the growth and development of $T$. aestivum, as well as the concentration of $\mathrm{N}, \mathrm{P}, \mathrm{Fe}$, and $\mathrm{Mn}$ in plant shoots in normal and saline soil. The findings suggest that Streptomyces isolate can be used as biofertilizers in saline soils. Recently, Khan et al. (2017) reported that the application of plant growth-promoting endophytic bacteria (PGPE) and jasmonic acid enhanced the growth of S. pimpinellifolium when exposed to salinity stress. The findings suggest that the salinity tolerance ability of PGPE could be attributed to the existence of glutathione-related genes in their genome.

\section{Role of ACC Deaminase Producing PGPM in Abiotic Stress Tolerance}

Many aspects of plant growth are regulated by ethylene concentrations and ethylene biosynthesis is tightly controlled by transcriptional and post-transcriptional factors, which are mediated by biotic and abiotic stresses (e.g., drought and salinity; Hardoim et al., 2008). The phytohormone ethylene regulates plant homeostasis in response to stress conditions, leading to reduced plant growth and development. ACC deaminase producing bacteria can modulate plant ethylene levels through cleaving ACC into $\alpha$-ketobutyrate and ammonia, therefore, ameliorating stress and promoting plant growth under adverse conditions (Glick et al., 2007). ACC deaminase producing Achromobacter piechaudii ARV8 conferred IST against salt in S. lycopersicum (Mayak et al., 2004). Under drought conditions, ACC deaminase producing PGPB A. piechaudii ARV8 greatly enhanced the seedling fresh and dry weight of L. esculentum and $C$. annuum while reduced the production of ethylene (Mayak et al., 2004). It was found that only wild type ACC deaminase-containing PGPB (not mutant PGPB that lack ACC deaminase) could protect plants from ethylene-induced growth inhibition, regardless of whether those bacteria are rhizobacteria or endophytes in nature (Forni et al., 2017).

\section{Microbial Exopolysaccharide Production}

The dynamic and complex interactions between microbes, plant roots, and soils in the rhizosphere can alter the soil physicochemical and structural properties (Ma et al., 2016). The extracellular polysaccharides produced by soil microorganisms can bind soil particles together to form microand/or macroaggregates, where plant roots, bacteria, fungal hyphae fit in the pores between microaggregates and are involved in macroaggregate stabilization (Naseem et al., 2018). The EPS producing bacteria were found to enhance the plant tolerance to drought and salinity stresses due to their ability to optimize soil structure (Sandhya et al., 2009; Naseem et al., 2018). Recently, Khan and Bano (2019) demonstrated that EPS produced by PGPB consortia positively affected drought tolerance and plant growth through the improvement of soil moisture contents. In the rhizosphere soil, bacterial EPS form a rhizosheath around the roots and hence protect plant host from desiccation for a longer period. Under salinity stress, EPS may bind to cations (e.g., $\mathrm{Na}^{+}$), making it unavailable to plants for their uptake. The co-inoculation of Rhizobium and Pseudomonas resulted in increased proline production along with decreased electrolyte leakage, maintenance of leaf relative water content, and selective uptake of $\mathrm{K}^{+}$, therefore, eventually improving salt tolerance in Z. mays (Bano and Fatima, 2009).

\section{Alteration of the Antioxidant Defense System}

As mentioned above, abiotic stress such as high salinity or drought induces overproduction of ROS, leading to altered 
cellular redox homeostasis. The elevated ROS level causes inactivation of membrane-bound proteins, diminished membrane fluidity, DNA damage, inhibition of protein synthesis, and enzymatic activities. There is substantial evidence indicating that PGPM inoculated plants can survive under abiotic stressinduced oxidative stress by manipulation of antioxidant enzymes (Kim et al., 2014). For instance, Pedranzani et al. (2016) found that the application of AMF Rhizophagus irregularis improved the physiological performance of Digitaria eriantha under drought, salinity, and cold stresses through the upregulation of antioxidant enzyme activity (e.g., CAT and APX) and jasmonate synthesis. Recently, Ma et al. (2017) reported that the application of plant growth-promoting endophytic bacterium ASS1 stimulated the activity of CAT and SOD under various stress conditions (e.g., drought, multi-metals, and drought + multi-metals). Although PGPM inoculated plants have been proved to mitigate the oxidative damage, the underlying mechanisms behind alterations in antioxidant enzyme activities that caused by PGPM are scarcely known. Many factors, such as host plant species, PGPM type, and strain, as well as type, degree, and duration of abiotic stress can be responsible for such alterations in enzymatic levels.

\section{Microbial Osmolytes Production}

Plant growth-promoting microorganisms can produce compatible osmolytes in response to drought or salinity stress, which act synergistically with osmolytes (e.g., proline, trehalose, and polyamines) secreted from plants and, thus, promote plant growth and development (Paul et al., 2008). The capacity to accumulate proline under stress conditions has been greatly correlated with stress tolerance in plants (Claussen, 2005). Under drought and salinity stresses, proline shows great potential to adjust cytosolic acidity and diminish lipid peroxidation by directly scavenging ROS and stabilizing proteins and membranes (Gill and Tuteja, 2010). There have been numerous reports implicating that plants inoculated with PGPM manifest increased proline content, which helps plants to cope with drought and salinity stress (Bharti et al., 2014; (Shintu and Jayaram, 2015). However, it is still not clear whether it is absorbed from rhizosphere soils or due to the upregulation of the proline biosynthesis pathway. On the contrary, several studies observed that the inoculation of PGPB decreased the proline content in plants exposed to drought and salinity stresses (Ma et al., 2017, 2019a; Singh and Jha, 2017). This is because PGPM may counteract the adverse effects of drought and salinity by inducing the regulation of osmotic balance and maintaining the bioenergetics of plant cells.

Moreover, as a highly sable glucoside, trehalose plays an important role in diminishing the damage to plant cells from drought and salinity. Rodriguez Salazar et al. (2009) observed that inoculation of $Z$. mays with Azospirillum brasilense overexpressing trehalose biosynthetic genes increased trehalose accumulation, consequently conferring drought tolerance or osmotolerance. This may be attributed to the ability of trehalose to stabilize membranes and proteins. Recently, a higher accumulation of trehalose was found in mycorrhizal plants under salt stress compared to non-mycorrhizal plants. This can be due to AMF-stimulated enhanced activities of enzymes responsible for the biosynthesis of trehalose (e.g., trehalose-6-phosphate synthase and trehalose-6-phosphate phosphatase) and lower activity of trehalose degrading enzyme (e.g., trehalase; Garg and Pandey, 2016).

Polyamines are biogenic amines having aliphatic nitrogen structure that exist in almost all organisms and are widely implicated in diverse plant growth and development processes, such as cell division and differentiation, root elongation, floral development, fruit maturation, senescence, programmed cell death, and DNA replication, transcription and translation (Alcazar et al., 2011). Cassan et al. (2009) found that inoculation of cadaverine (polyamine)-producing A. brasilense Az39 significantly promoted the root growth of Oryza seedlings under osmotic stress (Cassan et al., 2009). Recently, a pot experiment was conducted by Zhang et al. (2019b) to evaluate the role of AMF in root polyamine homeostasis, activities, and gene expression of polyamine-related synthesizing and degrading enzymes in Poncirus trifoliata under drought stress. The results show that mycorrhizal application induced higher putrescine and cadaverine with higher activity of polyamine catabolic enzymes and putrescine synthases under drought stress, demonstrating that mycorrhizas can improve plant drought tolerance through modulation of polyamine metabolism.

\section{CONCLUSION AND FUTURE PERSPECTIVES}

Considering the global climate change scenario, the main obstacle to global food security is sustained loss of crops due to abiotic stresses (particularly drought and salinity). In the past decades, great progress has been made in understanding how abiotic stresses affect plant growth and yield, and how the plant respond/ adapt to these stresses. The duration and severity of drought or salinity exposed have undoubtedly pivotal roles in examining how plants respond to these stresses as elucidated in Figure 1.

In terms of drought, stomata close progressively along with a parallel reduction in water-use efficiency and net photosynthetic activity. Apart from other parameters, the alterations in photosynthetic pigments are closely correlated with drought tolerance. Self-protective responses to the stress at the leaf level must then be triggered quickly to protect the photosynthetic machinery from being irreversibly damaged. Scavenging of ROS by enzymatic and non-enzymatic systems, cell membrane stability, expression of stress-responsive genes, and proteins are essential mechanisms of drought tolerance. Moreover, metabolite adjustments strongly contribute to drought adaptation, particularly polyphenols, lipophilic compounds, and some TCA cycle metabolites are involved in defense and protection, while other compounds, such as carbohydrates, amino acids, and polyols, contribute to osmoregulation.

Plant response to salinity follows a biphasic model, wherein an early phase shows a similarity with drought (osmotic stress) and in the long-term induce ion toxicity. In the first phase, growth falls significantly, and stomata closure occurs in response to water potential decline. In the second phase, ions accumulations, particularly $\mathrm{Na}^{+}$, affects photosynthetic 
components such as enzymes and pigments, and increase oxidative stress. ROS play a dual role in salt stress response, functioning as toxic by-products of stress, as well as a signal molecule activating several pathways leading to protective responses that are also common to drought stress.

Plant-associated microorganisms can be considered as major components of the ecosystems and play an essential role in improving plant adaptation/evolution to climatic stresses (such as drought and salinity). In this regard, microbes can rescue plants from the negative consequences of drought and salinity through various mechanisms, such as solubilization of nutrients (N, P, K, and Fe), IST, and production of phytohormones (IAA, cytokinin, ABA, and GA), EPS, and ACC deaminase. Given the fundamental understanding of these mechanisms involved in plant-PGPM interactions, it is expected that the practical use of PGPM in agricultural fields will grow dramatically to improve plant survival to environmental changes. Nevertheless, it is not clear whether the mechanisms involved in PGPM induced amelioration of drought stress are different from those of salinity stress. Further research is required to provide evidence

\section{REFERENCES}

AbdElgawad, H., Zinta, G., Hegab, M. M., Pandey, R., Asard, H., and Abuelsoud, W. (2016). High salinity induces different oxidative stress and antioxidant responses in maize seedlings organs. Front. Plant Sci. 7:276. doi: 10.3389/ fpls.2016.00276

Abuqamar, S., Luo, H. L., Laluk, K., Mickelbart, M. V., and Mengiste, T. (2009). Crosstalk between biotic and abiotic stress responses in tomato is mediated by the AIM1 transcription factor. Plant J. 58, 347-360. doi: 10.1111/ j.1365-313X.2008.03783.x

Alcazar, R., Bitrián, M., Bartels, D., Koncz, C., Altabella, T., and Tiburcio, A. F. (2011). Polyamine metabolic canalization in response to drought stress in Arabidopsis and the resurrection plant Craterostigma plantagineum. Plant Signal. Behav. 6, 243-250. doi: 10.4161/psb.6.2.14317

Alves, A. A. C., and Setter, T. L. (2004). Response of cassava leaf area expantion to water deficit: cell proliferation, cell expansion and delayed development. Ann. Bot. 94, 605-613. doi: 10.1093/aob/mch179

Anjum, S. A., Ashraf, U., Tanveer, M., Khan, I., Hussain, S., Shahzad, B., et al. (2017). Drought induced changes in growth, osmolyte accumulation and antioxidant metabolism of three maize hybrids. Front. Plant Sci. 8:69. doi: $10.3389 /$ fpls.2017.00069

Araújo, M., Ferreira de Oliveira, J. M. P., Santos, C., Moutinho-Pereira, J., Correia, C., and Dias, M. C. (2019). Responses of olive plants exposed to different irrigation treatments in combination with heat shock: physiological and molecular mechanisms during exposure and recovery. Planta 249, 1583-1598. doi: 10.1007/s00425-019-03109-2

Bahadur, A., Batool, A., Nasir, F., Jiang, S., Mingsen, Q., Zhang, Q., et al. (2019). Mechanistic insights into arbuscular mycorrhizal fungi-mediated drought stress tolerance in plants. Int. J. Mol. Sci. 20:4199. doi: 10.3390/ijms20174199

Bano, A., and Fatima, M. (2009). Salt tolerance in Zea mays (L.) following inoculation with Rhizobium and Pseudomonas. Biol. Fertil. Soils 45, 405-413. doi: 10.1007/s00374-008-0344-9

Barassi, C. A., Ayrault, G., Creus, C. M., Sueldo, R. J., and Sobero, M. T. (2006). Seed inoculation with Azospirillum mitigates $\mathrm{NaCl}$ effects on lettuce. Sci. Hortic. 109, 8-14. doi: 10.1016/j.scienta.2006.02.025

Barnard, R. L., Osborne, C. A., and Firestone, M. K. (2013). Responses of soil bacterial and fungal communities to extreme desiccation and rewetting. ISME J. 7, 2229-2241. doi: 10.1038/ismej.2013.104

Beinsan, C., Camen, D., Sumalan, R., and Babau, M. (2003). "Study concerning salt stress effect on leaf area dynamics and chlorophyll content in four bean local landraces from Banat area." in 44th Croatian and 4th International Symposium on Agriculture. of underlying similarities and differences in microbe induced drought and salinity tolerance, basing on innovations in mirroring microbial interactions found in nature.

\section{AUTHOR CONTRIBUTIONS}

YM developed the ideas and wrote and revised the manuscript. MD wrote and revised the manuscript. HF was the project sponsor, and revised the manuscript. All authors contributed to the article and approved the submitted version.

\section{FUNDING}

This work is carried out at the R\&D Unit Center for Functional Ecology - Science for People and the Planet (CFE), with reference UIDB/04004/2020, financed by FCT/MCTES through national funds (PIDDAC). The FCT supported the research contracts of YM (SFRH/BPD/76028/2011) and MC Dias (SFRH/BPD/100865/2014).

Berthomieu, P., Conejero, G., Nublat, A., Brackenbury, W. J., Lambert, C. Savio, C., et al. (2003). Functional analysis of AtHKT1 in Arabidopsis shows that $\left.\mathrm{Na}^{+}\right)$recirculation by the phloem is crucial for salt tolerance. $E M B O$ J. 22, 2004-2014. doi: 10.1093/emboj/cdg207

Bharti, N., Barnawal, D., Awasthi, A., Yadav, A., and Kalra, A. (2014). Plant growth promoting rhizobacteria alleviate salinity induced negative effects on growth, oil content and physiological status in Mentha arvensis. Acta Physiol. Plant. 36, 45-60. doi: 10.1007/s11738-013-1385-8

Bogeat-Triboulot, M. B., Brosche, M., Renaut, J., Jouve, L., Le Thiec, D., Fayyaz, P., et al. (2007). Gradual soil water depletion results in reversible changes of gene expression, protein profiles, ecophysiology, and growth performance in Populus euphratica, a poplar growing in arid regions. Plant Physiol. 143, 876-892. doi: 10.1104/pp.106.088708

Bouskill, N. J., Lim, H. C., Borglin, S., Salve, R., Wood, T. E., Silver, W. L., et al. (2013). Pre-exposure to drought increases the resistance of tropical forest soil bacterial communities to extended drought. ISME J. 7, 384-394. doi: 10.1038/ismej.2012.113

Bresson, J., Varoquaux, F., Bontpart, T., Touraine, B., and Vile, D. (2013). The PGPR strain Phyllobacterium brassicacearum STM196 induces a reproductive delay and physiological changes that result in improved drought tolerance in Arabidopsis. New Phytol. 200, 558-569. doi: 10.1111/nph.12383

Brunner, I., Herzog, C., Dawes, M. A., Arend, M., and Sperisen, C. (2015). How tree roots respond to drought. Front. Plant Sci. 6:547. doi: 10.3389/fpls.2015.00547

Burke, J. J. (2007). Evaluation of source leaf responses to water-deficit stresses in cotton using a novel stress bioassay. Plant Physiol. 143, 108-121. doi: 10.1104/pp.106.087783

Busby, P. E., Soman, C., Wagner, M. R., Friesen, M. L., Kremer, J., Bennett, A., et al. (2017). Research priorities for harnessing plant microbiomes in sustainable agriculture. PLoS Biol. 15:e2001793. doi: 10.1371/journal.pbio.2001793

Cassan, F., Maiale, S., Masciarelli, O., Vidal, A., Luna, V., and Ruiz, O. (2009). Cadaverine production by Azospirillum brasilense and its possible role in plant growth promotion and osmotic stress mitigation. Eur. J. Soil Biol. 45, 12-19. doi: 10.1016/j.ejsobi.2008.08.003

Chandlee, J. M. (2001). Current molecular understanding of the genetically programmed process of leaf senescence. Physiol. Plant. 113, 1-8. doi: 10.1034/j. 1399-3054.2001.1130101.x

Chaparzadeh, N., D’Amico, M. L., Khavari-Nejad, R. A., Izzo, R., and Navari-Izzo, F. (2004). Antioxidative responses of Calendula officinalis under salinity conditions. Plant Physiol. Biochem. 42, 695-701. doi: 10.1016/j.plaphy.2004.07.001

Chaves, M. M., Flexas, J., and Pinheiro, C. (2009). Photosynthesis under drought and salt stress: regulation mechanisms from whole plant to cell. Ann. Bot. 103, 551-560. doi: 10.1093/aob/mcn 125 
Cheng, Y. T., Zhang, L., and He, S. Y. (2019). Plant-microbe interactions facing environmental challenge. Cell Host Microbe 26, 183-192. doi: 10.1016/j. chom.2019.07.009

Cheong, J. J., and Choi, Y. D. (2003). Methyl jasmonate as a vital substance in plants. Trends Genet. 19, 409-413. doi: 10.1016/S0168-9525(03)00138-0

Claussen, W. (2005). Proline as a measure of stress in tomato plants. Plant Sci. 168, 241-248. doi: 10.1016/j.plantsci.2004.07.039

Comas, L. H., Becker, S. R., Cruz, V. M. V., Byrne, P. F., and Dierig, D. A. (2013). Root traits contributing to plant productivity under drought. Front. Plant Sci. 4:442. doi: 10.3389/fpls.2013.00442

Compant, S., van der Heijden, M. G. A., and Sessitsch, A. (2010). Climate change effects on beneficial plant-microorganism interactions. FEMS Microbiol. Ecol. 73, 197-214. doi: 10.1111/j.1574-6941.2010.00900.x

Conde, A., Silva, P., Agasse, A., Conde, C., and Geros, H. (2011). Mannitol transport and mannitol dehydrogenase activities are coordinated in Olea europaea under salt and osmotic stresses. Plant Cell Physiol. 52, 1766-1775. doi: $10.1093 / \mathrm{pcp} / \mathrm{pcr} 121$

Courtois, B., Mclaren, G., Sinha, P. K., Prasad, K., Yadav, R., and Shen, L. (2000). Mapping QTLs associated with drought avoidance in upland rice. Mol. Breed. 6, 55-66. doi: 10.1023/A:1009652326121

Cramer, G. R., Ergul, A., Grimplet, J., Tillett, R. L., Tattersall, E. A., Bohlman, M. C., et al. (2007). Water and salinity stress in grapevines: early and late changes in transcript and metabolite profiles. Funct. Integr. Genomics 7, 111-134. doi: 10.1007/s10142-006-0039-y

Das, K., and Roychoudhury, A. (2014). Reactive oxygen species (ROS) and response of antioxidants as ROS-scavengers during environmental stress in plants. Front. Environ. Sci. 2:53. doi: 10.3389/fenvs.2014.00053

Deinlein, U., Stephan, A. B., Horie, T., Luo, W., Xu, G., and Schroeder, J. I. (2014). Plant salt-tolerance mechanisms. Trends Plant Sci. 19, 371-379. doi: 10.1016/j.tplants.2014.02.001

Demetriou, G., Neonaki, C., Navakoudis, E., and Kotzabasis, K. (2007). Salt stress impact on the molecular structure and function of the photosynthetic apparatus - the protective role of polyamines. Biochim. Biophys. Acta 1767, 272-280. doi: 10.1016/j.bbabio.2007.02.020

Di Ferdinando, M., Brunetti, C., Agati, G., and Tattini, M. (2014). Multiple functions of polyphenols in plants inhabiting unfavorable Mediterranean areas. Environ. Exp. Bot. 103, 107-116. doi: 10.1016/j.envexpbot.2013. 09.012

Dias, M., Azevedo, C., Costa, M., Pinto, G., and Santos, C. (2014). Melia azedarach plants show tolerance properties to water shortage treatment: an ecophysiological study. Plant Physiol. Biochem. 75, 123-127. doi: 10.1016/j. plaphy.2013.12.014

Dias, M. C., and Brüggemann, W. (2011). Limitations of photosynthesis in Phaseolus vulgaris under drought stress: gas exchange, chlorophyll fluorescence and Calvin cycle enzymes. Photosynthetica 48, 96-102. doi: 10.1007/ s11099-010-0013-8

Dimkpa, C., Weinand, T., and Ash, F. (2009). Plant-rhizobacteria interactions alleviate abiotic stress conditions. Plant Cell Environ. 32, 1682-1694. doi: 10.1111/j.1365-3040.2009.02028.x

Dodd, I. C., and Perez-Alfocea, F. (2012). Microbial amelioration of crop salinity stress. J. Exp. Bot. 63, 3415-3428. doi: 10.1093/jxb/ers033

Egamberdieva, D., and Kucharova, Z. (2009). Selection for root colonizing bacteria stimulating wheat growth in saline soils. Biol. Fertil. Soils 45, 563-571. doi: 10.1007/s00374-009-0366-y

Egamberdiyeva, D. (2007). The effect of plant growth promoting bacteria on growth and nutrient uptake of maize in two different soils. Appl. Soil Ecol. 36, 184-189. doi: 10.1016/j.apsoil.2007.02.005

Eke, P., Kumar, A., Sahu, K. P., Wakam, L. N., Sheoran, N., Ashajyothi, M., et al. (2019). Endophytic bacteria of desert cactus (Euphorbia trigonas mill) confer drought tolerance and induce growth promotion in tomato (Solanum lycopersicum L.). Microbiol. Res. 228:126302. doi: 10.1016/j.micres.2019.126302

El-Maarouf-Bouteau, H., Sajjad, Y., Bazin, J., Langlade, N., Cristescu, S. M., Balzergue, S., et al. (2015). Reactive oxygen species, abscisic acid and ethylene interact to regulate sunflower seed germination. Plant Cell Environ. 38, 364-374. doi: 10.1111/pce.12371

Eyidogan, F., Oz, M. T., Yucel, M., and Oktem, H. A. (2012). "Signal transduction of phytohormones under abiotic stresses" in Phytohormones and abiotic stress tolerance in plants. eds. N. A. Khan, R. Nazar, N. Iqbal and N. A. Anjum (Berlin: Springer), 1-48.
Fàbregas, N., and Fernie, A. R. (2019). The metabolic response to drought. J. Exp. Bot. 70, 1077-1085. doi: 10.1093/jxb/ery437

Fàbregas, N., Lozano-Elena, F, Blasco-Escámez, D., Tohge, T., Martínez-Andújar, C., Albacete, A., et al. (2018). Overexpression of the vascular brassinosteroid receptor BRL3 confers drought resistance without penalizing plant growth. Nat. Commun. 9:4680. doi: 10.1038/s41467-018-06861-3

Fahad, S., and Bano, A. (2012). Effect of salicylic acid on physiological and biochemical characterization of maize grown in saline area. Pak. J. Bot. 44, 1433-1438.

Fahad, S., Hussain, S., Matloob, A., Khan, F. A., Khaliq, A., and Saud, S. (2015). Phytohormones and plant responses to salinity stress: a review. Plant Growth Regul. 75, 391-340. doi: 10.1007/s10725-014-0013-y

Fathi, A., and Tari, D. B. (2016). Effect of drought stress and its mechanism in plants. Int. J. Life Sci. 10, 1-6. doi: 10.3126/ijls.v10i1.14509

Forni, C., Duca, D., and Glick, B. R. (2017). Mechanisms of plant response to salt and drought stress and their alteration by rhizobacteria. Plant Soil 410, 335-356. doi: 10.1007/s11104-016-3007-x

Frago, E., Mala, M., Weldegergis, B. T., Yang, C., McLean, A., Godfray, H. C. J., et al. (2017). Symbionts protect aphids from parasitic wasps by attenuating herbivore-induced plant volatiles. Nat. Commun. 8:1860. doi: 10.1038/ s41467-017-01935-0

Fraire-Velázquez, S., and Balderas-Hernández, V. E. (2013). "Abiotic stress in plants and metabolic responses" in Abiotic stress-plant responses and applications in agriculture. eds. K. Vahdati and C. Leslie (New York: InTech Open Science), 25-48.

Friesen, M. L., Porter, S. S., Stark, S. C., Von Wettberg, E. J., Sachs, J. L., and Martinez-Romero, E. (2011). Microbially mediated plant functional traits. Annu. Rev. Ecol. Evol. Syst. 42, 23-46. doi: 10.1146/annurev-ecolsys-102710-145039

Gall, H., Philippe, F., Domon, J. M., Gillet, F., Pelloux, J., and Rayon, C. (2015). Cell wall metabolism in response to abiotic stress. Plants 4, 112-166. doi: 10.3390/plants4010112

Galmés, J., Ribas-Carbó, M., Medrano, H., and Flexas, J. (2011). Rubisco activity in Mediterranean species is regulated by the chloroplastic $\mathrm{CO}_{2}$ concentration under water stress. J. Exp. Bot. 62, 653-665. doi: 10.1093/jxb/erq303

Gao, S., Ouyang, C., Wang, S., Xu, Y., Tang, L., and Chen, F. (2008). Effects of salt stress on growth, antioxidant enzyme and phenylalanine ammonialyase activities in Jatropha curcas L. seedlings. Plant Soil Environ. 54, 374-381. doi: 10.17221/410-PSE

Garg, N., and Pandey, R. (2016). High effectiveness of exotic arbuscular mycorrhizal fungi is reflected in improved rhizobial symbiosis and trehalose turnover in Cajanus cajan genotypes grown under salinity stress. Fungal Ecol. 21, 57-67. doi: 10.1016/j.funeco.2016.04.001

Geigenberger, P., Reimholz, R., Geiger, M., Merlo, L., Canale, V., and Stitt, M. (1997). Regulation of sucrose and starch metabolism in potato tubers in response to short-term water deficit. Planta 201, 502-518. doi: 10.1007/ s004250050095

Gill, S. S., and Tuteja, N. (2010). Reactive oxygen species and antioxidant machinery in abiotic stress tolerance in crop plants. Plant Physiol. Biochem. 48, 909-930. doi: 10.1016/j.plaphy.2010.08.016

Giné-Bordonaba, J., and Terry, L. A. (2016). Effect of deficit irrigation and methyl jasmonate application on the composition of strawberry (Fragaria $x$ ananassa) fruit and leaves. Sci. Hortic. 199, 63-70. doi: 10.1016/j. scienta.2015.12.026

Glick, B. R., Cheng, Z., Czarny, J., and Duan, J. (2007). Promotion of plant growth by ACC deaminase producing soil bacteria. Eur. J. Plant Pathol. 119, 329-339. doi: 10.1007/s10658-007-9162-4

Golldack, D., Li, C., Mohan, H., and Probst, N. (2014). Tolerance to drought and salt stress in plants: unraveling the signaling networks. Front. Plant Sci. 5:151. doi: 10.3389/fpls.2014.00151

González-Guzmán, M., Apostolova, N., Bellés, J. M., Barrero, J. M., Piqueras, P., Ponce, M. R., et al. (2002). The short-chain alcohol dehydrogenase ABA2 catalyzes the conversion of xanthoxin into abscisic aldehyde. Plant Cell 14, 1833-1846. doi: 10.1105/tpc.002477

Gould, K. S., Jay-Allemand, C., Logan, B. A., Baissac, Y., and Bidel, L. P. R. (2018). When are foliar anthocyanins useful to plants? Re-evaluation of the photoprotection hypothesis using Arabidopsis thaliana mutants that differ in anthocyanin accumulation. Environ. Exp. Bot. 154, 11-22. doi: 10.1016/j. envexpbot.2018.02.006

Gould, K. S., McKelvie, J., and Markham, K. R. (2002). Do anthocyanins function as antioxidants in leaves? Imaging of $\mathrm{H}_{2} \mathrm{O}_{2}$ in red and green leaves 
after mechanical injury. Plant Cell Environ. 25, 1261-1269. doi: 10.1046/j.1365-3040.2002.00905.x

Gray, S. B., and Brady, S. M. (2016). Plant developmental responses to climate change. Dev. Biol. 419, 64-77. doi: 10.1016/j.ydbio.2016.07.023

Guo, J., Hatt, S., He, K., Chen, J., Francis, F., and Wang, Z. (2017). Nine facultative endosymbionts in aphids. A review. J. Asia Pac. Entomol. 20, 794-801. doi: 10.1016/j.aspen.2017.03.025

Halo, B. A., Al-Yahyai, R. A., and Al-Sadi, A. M. (2020). An endophytic Talaromyces omanensis enhances reproductive, physiological and anatomical characteristics of drought-stressed tomato. J. Plant Physiol. 249:153163. doi: 10.1016/j.jplph.2020.153163

Hardoim, P. R., Van Verbeek, L. S., and Van Elsas, J. D. (2008). Properties of bacterial endophytes and their proposed role in plant growth. Trends Microbiol. 16, 463-471. doi: 10.1016/j.tim.2008.07.008

Hare, P. D., Cress, W. A., and Staden, J. V. (1998). Dissecting the roles of osmolyte accumulation during stress. Plant Cell Environ. 21:535. doi: 10.1046/j. 1365-3040.1998.00309.x

Harrison, M. A. (2012). "Cross-talk between phytohormone signalling pathways under both optimal and stressful environmental conditions" in Phytohormones and abiotic stress tolerance in plants. eds. N. A. Khan, R. Nazar, N. Iqbal and N. A. Anjum (Berlin: Springer), 49-76.

Hasibeder, R., Fuchslueger, L., Richter, A., and Bahn, M. (2015). Summer drought alters carbon allocation to roots and root respiration in mountain grassland. New Phytol. 205, 1117-1127. doi: 10.1111/nph.13146

Hatzig, S. V., Nuppenau, J. N., Snowdon, R. J., and Schiessl, S. V. (2018). Drought stress has transgenerational effects on seeds and seedlings in winter oilseed rape (Brassica napus L.). BMC Plant Biol. 18:297. doi: 10.1186/s12870-018-1531-y

Henry, A., Doucette, W., Norton, J., and Bugbee, B. (2007). Changes in crested wheatgrass root exudation caused by flood, drought, and nutrient stress. $J$. Environ. Qual. 36, 904-912. doi: 10.2134/jeq2006.0425sc

Huang, G. -T., Ma, S. -L., Bai, L. P., Zhang, L., Ma, H., Jia, P., et al. (2012). Signal transduction during cold, salt, and drought stresses in plants. Molec. Biol. Rep. 39, 969-987. doi: 10.1007/s11033-011-0823-1

Hummel, I., Pantin, F., Sulpice, R., Piques, M., Rolland, G., Dauzat, M., et al. (2010). Arabidopsis plants acclimate to water deficit at low cost through changes of carbon usage: an integrated perspective using growth, metabolite, enzyme, and gene expression analysis. Plant Physiol. 154, 357-372. doi: 10.1104/pp.110.157008

Hussain, M. B., Zahir, Z. A., Asghar, H. N., and Asghar, M. (2014). Exopolysaccharides producing rhizobia ameliorate drought stress in wheat. Int. J. Agric. Biol. 16, 3-13. doi: 10.1371/journal.pone.0222302

Iqbal, N., Umar, S., Khan, N. A., and Khan, M. I. R. (2014). A new perspective of phytohormones in salinity tolerance: regulation of proline metabolism. Environ. Exp. Bot. 100, 34-42. doi: 10.1016/j.envexpbot.2013.12.006

Isah, T. (2019). Stress and defense responses in plant secondary metabolites production. Biol. Res. 52:39. doi: 10.1186/s40659-019-0246-3

Jain, S., Vaishnav, A., Kasotia, A., Kumari, S., Gaur, R. K., and Choudhary, D. (2013). "Bacteria-induced systemic resistance and growth promotion in Glycine max L. merrill upon challenge inoculation with Fusarium exosporium" in Proceedings of the national academy of sciences, india - section B: Biological Sciences. 561-567.

Jaleel, C. A., Manivannan, P., Wahid, A., Farooq, M., Al-Juburi, H. J., Somasundaram, R., et al. (2009). Drought stress in plants: a review on morphological characteristics and pigments composition. Int. J. Agric. Biol. $11,100-105$.

Jorge, T. F., and António, C. (2018). "Plant metabolomics in a changing world: metabolite responses to abiotic stress combinations" in Plant, abiotic stress and responses to climate change. ed. V. Andjelkovic (New York: InTech Open Science), 111-132.

Jumali, S. S., Said, I. M., Ismail, I., and Zainal, Z. (2011). Genes induced by high concentration of salicylic acid in Mitragyna speciosa. Aust. J. Crop Sci. 5, 296-303.

Kaiser, W. M., Kaiser, G., Schöner, S., and Neimanis, S. (1981). Photosynthesis under osmotic stress. Differential recovery of photosynthetic activities of stroma enzymes, intact chloroplasts and leaf slices after exposure to high solute concentrations. Planta 153, 430-435. doi: 10.1007/BF00394981

Kamara, A. Y., Menkir, A., Badu-Apraku, B., and Ibikunle, O. (2003). The influence of drought stress on growth, yield and yield components of selected maize genotypes. J. Agric. Sci. 141, 43-50. doi: 10.1017/S0021859603003423
Kao, C. H. (2015). Mechanisms of salt tolerance in rice plants: compatible solutes and aquaporins. Crop Environ. Bioinform. 12, 73-82. doi: 10.1017/ S0021859603003423

Kaushal, M., and Wani, S. P. (2016). Rhizobacterial-plant interactions: strategies ensuring plant growth promotion under drought and salinity stress. Agric. Ecosyst. Environ. 231, 68-78. doi: 10.1016/j.agee.2016.06.031

Kefu, Z., Hai, F., San, Z., and Jie, S. (2003). Study on the salt and drought tolerance of Suaeda salsa and Kalanchoe claigremontiana under iso-osmotic salt and water stress. Plant Sci. 165, 837-844. doi: 10.1016/S0168-9452(03) 00282-6

Khan, N., and Bano, A. (2019). Exopolysaccharide producing rhizobacteria and their impact on growth and drought tolerance of wheat grown under rainfed conditions. PLoS One 14:e0222302. doi: 10.1371/journal.pone.0222302

Khan, A. L., Muneer, S., Kim, Y., Al-Rawahi, A., and Al-Harrasi, A. (2019). Silicon and salinity: crosstalk in crop-mediated stress tolerance mechanisms. Front. Plant Sci. 10:1429. doi: 10.3389/fpls.2019.01429

Khan, A. L., Waqas, M., Asaf, S., Kamrand, M., Shahzad, R., Bilal, S., et al. (2017). Plant growth-promoting endophyte Sphingomonas sp. LK11 alleviates salinity stress in Solanum pimpinellifolium. Environ. Exp. Bot. 133, 58-69. doi: 10.1016/j.envexpbot.2016.09.009

Khodary, S. E. A. (2004). Effect of salicylic acid on growth, photosynthesis and carbohydrate metabolism in salt stressed maize plants. Int. J. Agric. Biol. 6, 5-8.

Kim, K., Jang, Y. -J., Lee, S. -M., Oh, B. -T., Chae, J. -C., and Lee, K. -J. (2014). Alleviation of salt stress by Enterobacter sp. EJ01 in tomato and Arabidopsis is accompanied by up-regulation of conserved salinity responsive factors in plants. Mol. Cell 37, 109-117. doi: 10.14348/molcells.2014.2239

Kohler, J., Hernandez, J. A., Caravaca, F., and Roldan, A. (2009). Induction of antioxidant enzymes is involved in the greater effectiveness of a PGPR versus AM fungi with respect to increasing the tolerance of lettuce to severe salt stress. Environ. Exp. Bot. 65, 245-252. doi: 10.1016/j.envexpbot.2008.09.008

Koussevitzky, S., Suzuki, N., Huntington, S., Armijo, L., Sha, W., Cortes, D., et al. (2008). Ascorbate peroxidase 1 plays a key role in the response of Arabidopsis thaliana to stress combination. J. Biol. Chem. 283, 34197-34203. doi: $10.1074 /$ jbc.M806337200

Lafitte, H. R., Yongsheng, G., Yan, S., and Li, Z. K. (2007). Whole plant responses, key processes, and adaptation to drought stress: the case of rice. J. Exp. Bot. 58, 169-175. doi: 10.1093/jxb/erl101

Landouar-Arsivaud, L., Juchaux-Cachau, M., Jeauffre, J., Biolley, J. P., Maurousset, L., and Lemoine, R. M. (2011). The promoters of 3 celery salt-induced phloemspecific genes as new tools for monitoring salt stress responses. Plant Physiol. Biochem. 49, 2-8. doi: 10.1016/j.plaphy.2010.09.008

Lebon, E., Pellegrino, A., Louarn, G., and Lecoeur, J. (2006). Branch development controls leaf area dynamics in grapevine (Vitis vinifera) growing in drying soil. Ann. Bot. 98, 175-185. doi: 10.1093/aob/mcl085

Lemoine, R., La Camera, S., Atanassova, R., Dédaldéchamp, F., Allario, T., Pourtau, N., et al. (2013). Source-to-sink transport of sugar and regulation by environmental factors. Front. Plant Sci. 4:272. doi: 10.3389/fpls.2013.00272

Lesk, C., Rowhani, P., and Ramankutty, N. (2016). Influence of extreme weather disasters on global crop production. Nature 529, 84-87. doi: 10.1038/nature16467

Li, M., Guo, R., Jiao, Y., Jin, X., Zhang, H., and Shi, L. (2017). Comparison of salt tolerance in Soja based on metabolomics of seedling roots. Front. Plant Sci. 8:1101. doi: 10.3389/fpls.2017.01101

Liu, F., Xing, S., Ma, H., Du, Z., and Ma, B. (2013). Cytokinin producing, plant growth promoting rhizobacteria that confer resistance to drought stress in Platycladus orientalis container seedlings. Appl. Microbiol. Biotechnol. 97, 9155-9164. doi: 10.1007/s00253-013-5193-2

Lo Piccolo, E., Landi, M., Pellegrini, E., Agati, G., Giordano, C., Giordani, T., et al. (2018). Multiple consequences induced by epidermally-located anthocyanins in young, mature and senescent leaves of Prunus. Front. Plant Sci. 9:917. doi: 10.3389/fpls.2018.00917

Lohaus, G., Hussmann, M., Pennewiss, K., Schneider, H., Zhu, J. J., and Sattelmacher, B. (2000). Solute balance of a maize (Zea mays L.) source leaf as affected by salt treatment with special emphasis on phloem retranslocation and ion leaching. J. Exp. Bot. 51, 1721-1732. doi: 10.1093/ jexbot/51.351.1721

Ma, Y., Prasad, M. N. V., Rajkumar, M., and Freitas, H. (2011). Plant growth promoting rhizobacteria and endophytes accelerate phytoremediation of metalliferous soils. Biotechnol. Adv. 29, 248-258. doi: 10.1016/j.biotechadv.2010.12.001 
Ma, Y., Rajkumar, M., Moreno, A., Zhang, C., and Freitas, H. (2017). Serpentine endophytic bacterium Pseudomonas azotoformans ASS1 accelerates phytoremediation of soil metals under drought stress. Chemosphere 185, 75-85. doi: 10.1016/j.chemosphere.2017.06.135

Ma, Y., Rajkumar, M., Oliveira, R. S., Zhang, C., and Freitas, H. (2019a). Potential of plant beneficial bacteria and arbuscular mycorrhizal fungi in phytoremediation of metal-contaminated saline soils. J. Hazard. Mater. 379:120813. doi: 10.1016/j.jhazmat.2019.120813

Ma, Y., Rajkumar, M., Zhang, C., and Freitas, H. (2016). Inoculation of Brassica oxyrrhina with plant growth promoting bacteria for the improvement of heavy metal phytoremediation under drought conditions. J. Hazard. Mater. 320, 36-44. doi: 10.1016/j.jhazmat.2016.08.009

Ma, Y., Vosátka, M., and Freitas, H. (2019b). Editorial: beneficial microbes alleviate climatic stresses in plants. Front. Plant Sci. 10:595. doi: 10.3389/ fpls.2019.00595

Mailloux, R. J., Bériault, R., Lemire, J., Singh, R., Chénier, D. R., Hamel, R. D., et al. (2007). The tricarboxylic acid cycle, an ancient metabolic network with a novel twist. PLoS One 8:e690. doi: 10.1371/journal.pone.0000690

Malik, B., Pirzadah, T. B., Tahir, I., Rehman, R. U., Hakeem, K. R., and Abdin, M. Z. (2013). "Plant signalling response to reactive oxygen species" in Plant signaling: Understanding the molecular crosstalk. eds. K. R. Hakeem, R. U. Rehman and I. Tahir (New Delhi: Springer Science \& Business Media), 1-38.

Marshall, J. G., and Dumbroff, E. B. (1999). Turgor regulation via cell wall adjustment in white spruce. Plant Physiol. 119, 313-319. doi: 10.1104/ pp.119.1.313

Marshall, J. G., Dumbroff, E. B., Thalcher, B. J., Martin, B., and Blumwald, E. (1999). Synthesis and oxidative insolubilization of cell-wall proteins during osmotic stress. Planta 208, 401-408. doi: 10.1007/s004250050575

Martínez, J. P., Lutts, S., Schanck, A., Bajji, M., and Kinet, J. M. (2004). Is osmotic adjustment required for water stress resistance in the Mediterranean shrub Atriplex halimus L.? J. Plant Physiol. 161, 1041-1051. doi: 10.1016/j. jplph.2003.12.009

Mayak, S., Tirosh, T., and Glick, B. R. (2004). Plant growth-promoting bacteria confer resistance in tomato plants to salt stress. Plant Physiol. Biochem. 42, 565-572. doi: 10.1016/j.plaphy.2004.05.009

Mittler, R. (2006). Abiotic stress, the field environment and stress combination. Trends Plant Sci. 11, 15-19. doi: 10.1016/j.tplants.2005.11.002

Mittler, R., and Blumwald, E. (2015). The roles of ROS and ABA in systemic acquired acclimation. Plant Cell 27, 64-70. doi: 10.1105/tpc.114.133090

Mittova, V., Guy, M., Tal, M., and Volokita, M. (2004). Salinity up-regulates the antioxidative system in root mitochondria and peroxisomes of the wild salt-tolerant tomato species Lycopersicon pennellii. J. Exp. Bot. 55, 1105-1113. doi: $10.1093 / \mathrm{jxb} / \mathrm{erh} 113$

Miura, K., Okamoto, H., Okuma, E., Shiba, H., Kamada, H., Hasegawa, P. M., et al. (2013). SIZ1 deficiency causes reduced stomatal aperture and enhanced drought tolerance via controlling salicylic acid-induced accumulation of reactive oxygen species in Arabidopsis. Plant J. 73, 91-104. doi: 10.1111/ tpj. 12014

Miura, K., and Tada, Y. (2014). Regulation of water, salinity, and cold stress responses by salicylic acid. Front. Plant Sci. 5:4. doi: 10.3389/fpls.2014.00004

Munns, R. (2002). Comparative physiology of salt and water stress. Plant Cell Environ. 25, 239-250. doi: 10.1046/j.0016-8025.2001.00808.x

Munns, R., and Tester, M. (2008). Mechanisms of salinity tolerance. Annu. Rev. Plant Biol. 59, 651-681. doi: 10.1146/annurev.arplant.59.032607. 092911

Naseem, H., Ahsan, M., Shahid, M. A., and Khan, N. (2018). Exopolysaccharides producing rhizobacteria and their role in plant growth and drought tolerance. J. Basic Microbiol. 58, 1009-1022. doi: 10.1002/jobm.201800309

Navarro, A., Bañón, S., Conejero, W., and Sánchez-Blanco, M. J. (2008). Ornamental characters, ion accumulation and water status in Arbutus unedo seedlings irrigated with saline water and subsequent relief and transplanting. Environ. Exp. Bot. 62, 364-370. doi: 10.1016/j.envexpbot.2007.10.010

Naz, I., Bano, A., and Ul-Hassan, T. (2009). Isolation of phytohormones producing plant growth promoting rhizobacteria from weeds growing in Khewra salt range, Pakistan and their implication in providing salt tolerance to Glycine max L. Afr. J. Biotechnol. 8, 5762-5768. doi: 10.5897/AJB09.1176

Nichelmann, L., and Bilger, W. (2017). Quantification of light screening by anthocyanins in leaves of Berberis thunbergii. Planta 246, 1069-1082. doi: $10.1007 / \mathrm{s} 00425-017-2752-2$
Obata, T., and Fernie, A. R. (2012). The use of metabolomics to dissect plant responses to abiotic stresses. Cell. Mol. Life Sci. 69, 3225-3243. doi: 10.1007/ s00018-012-1091-5

Pandey, P., Ramegowda, V., and Senthil-Kumar, M. (2015). Shared and unique responses of plants to multiple individual stresses and stress combinations: physiological and molecular mechanisms. Front. Plant Sci. 6:723. doi: 10.3389/ fpls.2015.00723

Pascale, A., Proietti, S., Pantelides, I. S., and Stringlis, I. A. (2020). Modulation of the root microbiome by plant molecules: the basis for targeted disease suppression and plant growth promotion. Front. Plant Sci. 10:1741. doi: 10.3389/fpls.2019.01741

Pattanagul, W., and Thitisaksakul, M. (2008). Effect of salinity stress on growth and carbohydrate metabolism in three rice (Oryza sativa L.) cultivars differing in salinity tolerance. Indian J. Exp. Biol. 46, 736-742.

Paul, M. J., Primavesi, L. F., Jhurreea, D., and Zhang, Y. (2008). Trehalose metabolism and signalling. Annu. Rev. Plant Biol. 59, 417-441. doi: 10.1146/ annurev.arplant.59.032607.092945

Pedranzani, H., Rodríguezrivera, M., Gutiérrez, M., Porcel, R., Hause, B., and Ruizlozano, J. M. (2016). Arbuscular mycorrhizal symbiosis regulates physiology and performance of Digitaria eriantha plants subjected to abiotic stresses by modulating antioxidant and jasmonate levels. Mycorrhiza 26, 141-152. doi: 10.1007/s00572-015-0653-4

Penella, C., Landi, M., Guidi, L., Nebauer, S. G., Pellegrini, E., San Bautista, A., et al. (2016). Salt-tolerant rootstock increases yield of pepper under salinity through maintenance of photosynthetic performance and sinks strength. $J$. Plant Physiol. 193, 1-11. doi: 10.1016/j.jplph.2016.02.007

Peng, J., Liu, J., Zhang, L., Luo, J., Dong, H., Ma, Y., et al. (2016). Effects of soil salinity on sucrose metabolism in cotton leaves. PLoS One 11:e0156241. doi: 10.1371/journal.pone.0156241

Perdomo, J. A., Capó-Bauçà, S., Carmo-Silva, E., and Galmés, J. (2017). Rubisco and rubisco activase play an important role in the biochemical limitations of photosynthesis in rice, wheat, and maize under high temperature and water deficit. Front. Plant Sci. 8:490. doi: 10.3389/fpls.2017.00490

Pinheiro, C., and Chaves, M. M. (2011). Photosynthesis and drought: can we make metabolic connections from available data? J. Exp. Bot. 62, 869-882. doi: $10.1093 / \mathrm{jxb} / \mathrm{erq} 340$

Pommerrenig, B., Papini-Terzi, F. S., and Sauer, N. (2007). Differential regulation of sorbitol and sucrose loading into the phloem of Plantago major in response to salt stress. Plant Physiol. 144, 1029-1038. doi: 10.1104/pp.106.089151

Poorter, H., Niklas, K. J., Reich, P. B., Oleksyn, J., Poot, P., and Mommer, L. (2012). Biomass allocation to leaves, stems and roots: meta-analyses of interspecific variation and environmental control. New Phytol. 193, 30-50. doi: $10.1111 /$ j.1469-8137.2011.03952.x

Rahdari, P., and Hoseini, S. M. (2012). Drought stress, a review. Int. J. Agron. Plant Prod. 3, 443-446.

Rahdari, P., Hoseini, S. M., and Tavakoli, S. (2012). The studying effect of drought stress on germination, proline, sugar, lipid, protein and chlorophyll content in Purslane (Portulaca oleraceae L.) leaves. J. Med. Plant Res. 6, 1539-1547. doi: 10.5897/JMPR11.698

Rampino, P., Pataleo, S., Gerardi, C., and Perotta, C. (2006). Drought stress responses in wheat: physiological and molecular analysis of resistant and sensitive genotypes. Plant Cell Environ. 29, 2143-2152. doi: 10.1111/j.13653040.2006.01588.x

Raza, A., Razzaq, A., Mehmood, S. S., Zou, X., Zhang, X., Lv, Y., et al. (2019). Impact of climate change on crops adaptation and strategies to tackle its outcome: a review. Plants 8:34. doi: 10.1046/j.1365-2745.2003.00806.x

Razavi, F., Keyser, E., Riek, J., and Van Labeke, M. C. (2011). A method for testing drought tolerance in Fragaria based on fast screening for water deficit response and use of associated AFLP and EST candidate gene markers. Euphytica 180, 385-409. doi: 10.1007/s10681-011-0398-x

Ribeiro, D. M., and Barros, R. S. (2006). Sensitivity to ethylene as a major component in the germination of seeds of Stylosanthes humilis. Seed Sci. Res. 16, 37-45. doi: 10.1079/SSR2005233

Richter, J. A., Erban, A., Kopka, J., and Zorb, C. (2015). Metabolic contribution to salt stress in two maize hybrids with contrasting resistance. Plant Sci. 233, 107-115. doi: 10.1016/j.plantsci.2015.01.006

Rodriguez, R. J., Henson, J., Van Volkenburgh, E., Hoy, M., Wright, L., Beckwith, F., et al. (2008). Stress tolerance in plants via habitat-adapted symbiosis. ISME J. 2, 404-416. doi: 10.1038/ismej.2007.106 
Rodriguez Salazar, J., Suárez, R., Caballero-Mellado, J., and Iturriaga, G. (2009). Trehalose accumulation in Azospirillum brasilense improves drought tolerance and biomass in maize plants. FEMS Microbiol. Lett. 296, 52-59. doi: 10.1111/j. 1574-6968.2009.01614.x

Sadeghi, A., Karimi, E., Dahaji, P. A., Javid, M. G., Dalvand, Y., and Askari, H. (2012). Plant growth promoting activity of an auxin and siderophore producing isolate of Streptomyces under saline soil conditions. World J. Microbiol. Biotechnol. 28, 1503-1509. doi: 10.1007/s11274-011-0952-7

Samarah, N. H. (2005). Effects of drought stress on growth and yield of barley. Agron. Sustain. Dev. 25, 145-149. doi: 10.1051/agro:2004064

Sandhya, V., Ali, S. K. Z., Grover, M., Reddy, G., and Venkateswarlu, B. (2009). Alleviation of drought stress effects in sunflower seedlings by exopolysaccharides producing Pseudomonas putida strain GAP-P45. Biol. Fertil. Soils 46, 17-26. doi: 10.1007/s00374-009-0401-z

Santos-Medellín, C., Edwards, J., Liechty, Z., Nguyen, B., and Sundaresan, V. (2017). Drought stress results in a compartment-specific restructuring of the rice root-associated microbiomes. mBio 8:e00764-17. doi: 10.1128/ mBio.00764-17

Saradadevi, R., Palta, J. A., and Siddique, K. H. M. (2017). ABA-mediated stomatal response in regulating water use during the development of terminal drought in wheat. Front. Plant Sci. 8:1251. doi: 10.3389/fpls.2017.01251

Sarker, U., and Oba, S. (2018). Drought stress enhances nutritional and bioactive compounds, phenolic acids and antioxidant capacity of Amaranthus leafy vegetable. BMC Plant Biol. 18:258. doi: 10.1186/s12870-018-1484-1

Selvakumar, G., Panneerselvam, P., and Ganeshamurthy, A. N. (2012). "Bacterial mediated alleviation of abiotic stress in crops" in Bacteria in agrobiology: Stress management. ed. D. K. Maheshwari (Berlin Heidelberg: Springer-Verlag), 205-224.

Shahzad, R., Khan, A. L., Bilal, S., Waqas, M., Kang, S. M., and Lee, I. J. (2017). Inoculation of abscisic acid-producing endophytic bacteria enhances salinity stress tolerance in Oryza sativa. Environ. Exp. Bot. 136, 68-77. doi: 10.1016/j.envexpbot.2017.01.010

Sharma, A., Shahzad, B., Rehman, A., Bhardwaj, R., Landi, M., and Zheng, B. (2019). Response of phenylpropanoid pathway and the role of polyphenols in plants under abiotic stress. Molecules 24:2452. doi: 10.3390/ molecules 24132452

Shintu, P. V., and Jayaram, K. M. (2015). Phosphate solubilising bacteria (Bacillus polymyxa) - an effective approach to mitigate drought in tomato (Lycopersicon esculentum Mill). Trop. Plant Res. 2, 17-22.

Sibole, J. V., Cabot, C., Poschenrieder, C., and Barcelo, J. (2003). Ion allocation in two different salt-tolerant Mediterranean Medicago species. J. Plant Physiol. 160, 1361-1365. doi: 10.1078/0176-1617-00811

Siddiqi, E. H., Ashraf, M., Hussain, M., and Jamil, A. (2009). Assessment of intercultivar variation for salt tolerance in safflower (Carthamus tinctorius L.) using gas exchange characteristics as selection criteria. Pak. J. Bot. 41, 2251-2259.

Silva, P. O., Medina, E. F., Barros, R. S., and Ribeiro, D. M. (2014). Germination of salt-stressed seeds as related to the ethylene biosynthesis ability in three Stylosanthes species. J. Plant Physiol. 171, 14-22. doi: 10.1016/j.jplph.2013. 09.004

Silva, S., Santos, C., Serodio, J., Silva, A. M. S., and Dias, M. C. (2018). Physiological performance of drought-stressed olive plants when exposed to a combined heat-UV-B shock and after stress relief. Funct. Plant Biol. 45, 1233-1240. doi: 10.1071/FP18026

Singh, R. P., and Jha, P. N. (2017). The PGPR Stenotrophomonas maltophilia SBP-9 augments resistance against biotic and abiotic stress in wheat plants. Front. Microbiol. 8:1945. doi: 10.3389/fmicb.2017.01945

Singh, V. K., Singh, A. K., Singh, P. P., and Kumar, A. (2018). Interaction of plant growth promoting bacteria with tomato under abiotic stress: a review. Agric. Ecosyst. Environ. 267, 129-140. doi: 10.1016/j.agee.2018.08.020

Slama, I., Abdelly, C., Bouchereau, A., Flower, T., and Savouré, A. (2015). Diversity, distribution and roles of osmoprotective compounds accumulated in halophytes under abiotic stress. Ann. Bot. 115, 433-447. doi: 10.1093/ aob/mcu239

Smith, S., and De Smet, I. (2012). Root system architecture: insights from Arabidopsis and cereal crops. Philos. Trans. R. Soc. Lond. Ser. B Biol. Sci. 367, 1441-1452. doi: 10.1098/rstb.2011.0234

Soliman, S. S. M., Abouleish, M., Abou-Hashem, M. M. M., Hamoda, A. M., and El-Keblawy, A. A. (2019). Lipophilic metabolites and anatomical acclimatization of Cleome amblyocarpa in the drought and extra-water areas of the arid desert of UAE. Plants 8:132. doi: 10.3390/plants8050132

Song, F., Han, X., Zhu, X., and Herbert, S. J. (2012). Response to water stress of soil enzymes and root exudates from drought and non-drought tolerant corn hybrids at different growth stages. Can. J. Soil Sci. 92, 501-507. doi: 10.4141/cjss2010-057

Stoop, J. M. H., Williamson, J. D., and Mason Pharr, D. (1996). Mannitol metabolism in plants: a method for coping with stress. Trends Plant Sci. 1, 139-144. doi: 10.1016/S1360-1385(96)80048-3

Sui, N., Yang, Z., Liu, M., and Wang, B. (2015). Identification and transcriptomic profiling of genes involved in increasing sugar content during salt stress in sweet Sorghum leaves. BMC Genomics 16:534. doi: 10.3389/fpls.2018.00007

Suwa, R., Fujimaki, S., Suzui, N., Kawachi, N., Ishii, S., Sakamoto, K., et al. (2008). Use of positron-emitting tracer imaging system for measuring the effect of salinity on temporal and spatial distribution of $11 \mathrm{C}$ tracer and coupling between source and sink organs. Plant Sci. 175, 210-216. doi: 10.1016/j.plantsci.2008.03.022

Suwa, R., Nguyen, N. T., Saneoka, H., Moghaieb, R., and Fujita, K. (2006). Effect of salinity stress on photosynthesis and vegetative sink in tobacco plants. Soil Sci. Plant Nutr. 52, 243-250. doi: 10.1111/j.1747-0765.2006.00024.x

Taffouo, V. D., Wamba, O. F., Yombi, E., Nono, G. V., and Akoa, A. (2010). Growth, yield, water status and ionic distribution response of three bambara groundnut (Vigna subterranean (L.) verdc.) landraces grown under saline conditions. Int. J. Bot. 6, 53-58. doi: 10.3923/ijb.2010.53.58

Taïbi, K., Taïbi, F., Abderrahim, L. A., Ennajah, A., Belkhodja, M., and Mulet, J. M. (2016). Effect of salt stress on growth, chlorophyll content, lipid peroxidation and antioxidant defence systems in Phaseolus vulgaris L. S. Afr. J. Bot. 105, 306-312. doi: 10.1016/j.sajb.2016.03.011

Taji, T., Ohsumi, C., Iuchi, S., Seki, M., Kasuga, M., Kobayashi, M., et al. (2002). Important roles of drought- and cold-inducible genes for galactinol synthase in stress tolerance in Arabidopsis thaliana. Plant J. 29, 417-426. doi: 10.1046/j.0960-7412.2001.01227.x

Tewari, S., and Arora, N. K. (2014). Multifunctional exopolysaccharides from Pseudomonas aeruginosa PF23 involved in plant growth stimulation, biocontrol and stress amelioration in sunflower under saline conditions. Curr. Microbiol. 69, 484-494. doi: 10.1007/s00284-014-0612-x

Thiem, D., Gołębiewski, M., Hulisz, P., Piernik, A., and Hrynkiewicz, K. (2018). How does salinity shape bacterial and fungal microbiomes of Alnus glutinosa roots? Front. Microbiol. 9:651. doi: 10.3389/fmicb.2018.00651

Tiepo, A. N., Hertel, M. F., Rocha, S. S., Calzavara, A. K., De Oliveira, A. L. M., Pimenta, J. A., et al. (2018). Enhanced drought tolerance in seedlings of Neotropical tree species inoculated with plant growth-promoting bacteria. Plant Physiol. Biochem. 130, 277-288. doi: 10.1016/j.plaphy.2018.07.021

Todaka, D., Zhao, Y., Yoshida, T., Kudo, M., Kidokoro, S., Mizoi, J., et al. (2017). Temporal and spatial changes in gene expression, metabolite accumulation and phytohormone content in rice seedlings grown under drought stress conditions. Plant J. 90, 61-78. doi: 10.1111/tpj.13468

Ullah, A., Manghwar, H., Shaban, M., Khan, A. H., Akbar, A., Ali, U., et al. (2018). Phytohormones enhanced drought tolerance in plants: a coping strategy. Environ. Sci. Pollut. Res. Int. 25, 33103-33118. doi: 10.1007/s11356-018-3364-5

Van Zandt, P. A., Tobler, M. A., Mouton, E., Hasenstein, K. H., and Mopper, S. (2003). Positive and negative consequences of salinity stress for the growth and reproduction of the clonal plant, Iris hexagonal. J. Ecol. 91, 837-846. doi: 10.1046/j.1365-2745.2003.00806.x

Vasques, A. R., Pinto, G., Dias, M. C., Correia, C. M., Moutinho-Pereira, J. M., Vallejo, V. R., et al. (2016). Physiological response to drought in seedlings of Pistacia lentiscus (mastic tree). New For. 47, 119-130. doi: 10.1007/ s11056-015-9497-1

Vurukonda, S. S. K. P., Vardharajula, S., Shrivastava, M., and SkZ, A. (2016). Enhancement of drought stress tolerance in crops by plant growth promoting rhizobacteria. Microbiol. Res. 184, 13-24. doi: 10.1016/j.micres.2015.12.003

Walia, H., Wilson, C., Condamine, P., Liu, X., Ismai, A. M., and Close, T. J. (2007). Large-scale expression profiling and physiological characterization of jasmonic acid-mediated adaptation of barley to salinity stress. Plant Cell Environ. 30, 410-421. doi: 10.1111/j.1365-3040.2006.01628.x

Wang, Z., Li, G., Sun, H., Ma, L., Guo, Y., Zhao, Z., et al. (2018a). Effects of drought stress on photosynthesis and photosynthetic electron transport chain in young apple tree leaves. Biol. Open 7:bio035279. doi: 10.1242/bio. 035279 
Wang, T., Tohge, T., Ivakov, A. A., Mueller-Roeber, B., Fernie, A. R., Mutwil, M., et al. (2015). Salt-related MYB1 (SRM1) coordinates abscisic acid biosynthesis and signaling during salt stress in Arabidopsis. Plant Physiol. 169, 1027-1041. doi: $10.1104 /$ pp.15.00962

Wang, F., Wu, N., Zhang, L., Ahammed, G. J., Chen, X., Xiang, X., et al. (2018b). Light signaling-dependent regulation of photoinhibition and photoprotection in tomato. Plant Physiol. 176, 1311-1326. doi: 10.1104/pp.17.01143

Wani, S. H., Kumar, V., Shriram, V., and Sah, S. K. (2016). Phytohormones and their metabolic engineering for abiotic stress tolerance in crop plants. Crop J. 4, 162-176. doi: 10.1016/j.cj.2016.01.010

Whittaker, A., Bochicchio, A., Vazzana, C., Lindsey, G., and Farrant, J. (2001). Changes in leaf hexokinase activity and metabolite levels in response to drying in the desiccation-tolerant species Sporobolus stapfianus and Xerophyta viscosa. J. Exp. Bot. 52, 961-969. doi: 10.1093/jexbot/52.358.961

Wingler, A. (2017). Transitioning to the next phase: the role of sugar signaling throughout the plant life cycle. Plant Physiol. 176, 1075-1084. doi: 10.1104/ pp.17.01229

Wolters, H., and Jürgens, G. (2009). Survival of the flexible: hormonal growth control and adaptation in plant development. Nat. Rev. Genet. 10, 305-317. doi: $10.1038 / \mathrm{nrg} 2558$

Xu, L., Dan, N., Zhaobin, D., Tuesday, S., Grady, P., Hixson, K. K., et al. (2018). Drought delays development of the Sorghum root microbiome and enriches for monoderm bacteria. Proc. Natl. Acad. Sci. U. S. A. 115, E4284-E4293. doi: $10.1073 /$ pnas. 1717308115

Xu, Z., Zhou, G., and Shimizu, H. (2010). Plant responses to drought and rewatering. Plant Signal. Behav. 5, 649-654. doi: 10.4161/psb.5.6.11398

Yang, J., Kloepper, J. W., and Ryu, C. M. (2009). Rhizosphere bacteria help plants tolerate abiotic stress. Trends Plant Sci. 14, 1-4. doi: 10.1016/j. tplants.2008.10.004

Yang, Z., Li, J. L., Liu, L. N., Xie, Q., and Sui, N. (2020). Photosynthetic regulation under salt stress and salt-tolerance mechanism of sweet Sorghum. Front. Plant Sci. 10:1722. doi: 10.3389/fpls.2019.01722
Yildirim, E., and Taylor, A. G. (2005). Effect of biological treatments on growth of bean plans under salt stress. Annu. Rep. Bean Improv. Coop. 48, $176-177$.

Yu, S. M., Lo, S. F., and Ho, T. D. (2015). Source-sink communication: regulated by hormone, nutrient, and stress cross-signaling. Trends Plant Sci. 20, 844-857. doi: 10.1016/j.tplants.2015.10.009

Zhang, H., Kim, M. S., Sun, Y., Dowd, S. E., Shi, H., and Pare, P. W. (2008). Soil bacteria confer plant salt tolerance by tissue-specific regulation of the sodium transporter HKT1. Mol. Plant Microbe Interact. 21, 737-744. doi: 10.1094/MPMI-21-6-0737

Zhang, W. -W., Wang, C., Xue, R., and Wang, L. (2019a). Effects of salinity on the soil microbial community and soil fertility. J. Integr. Agric. 18, 1360-1368. doi: 10.1016/S2095-3119(18)62077-5

Zhang, L., Zhang, L., Sun, J., Zhang, Z., Ren, H., and Sui, X. (2013). Rubisco gene expression and photosynthetic characteristics of cucumber seedlings in response to water deficit. Sci. Hortic. 161, 81-87. doi: 10.1016/j. scienta.2013.06.029

Zhang, F., Zou, Y. N., Wu, Q. S., and Kuča, K. (2019b). Arbuscular mycorrhizas modulate root polyamine metabolism to enhance drought tolerance of trifoliate orange. Environ. Exp. Bot. 171:103926. doi: 10.1016/j. envexpbot.2019.103926

Conflict of Interest: The authors declare that the research was conducted in the absence of any commercial or financial relationships that could be construed as a potential conflict of interest.

Copyright (c) $2020 \mathrm{Ma}$, Dias and Freitas. This is an open-access article distributed under the terms of the Creative Commons Attribution License (CC BY). The use, distribution or reproduction in other forums is permitted, provided the original author(s) and the copyright owner(s) are credited and that the original publication in this journal is cited, in accordance with accepted academic practice. No use, distribution or reproduction is permitted which does not comply with these terms. 